Check for updates

Cite this: Mater. Chem. Front. 2020, 4, 821

Received 24th October 2019 Accepted 12th December 2019

DOI: $10.1039 / c 9 q m 00658 c$

rsc.li/frontiers-materials

\section{Carbon dots: a booming material for biomedical applications}

\author{
Wen Su, (D) † Hao Wu, (D) † Huimin Xu, Yang Zhang, * Yunchao Li, (D) Xiaohong Li (D) \\ and Louzhen Fan (D) *
}

\begin{abstract}
As one of the most promising nanomaterials for biomedical applications, carbon dots (CDs) hold great potential in the field of bioimaging, biosensing and biotherapy due to their low cytotoxicity, high water solubility, favorable biocompatibility, good photostability, tunable fluorescence emission and excitation. In this review, we will provide an update on the latest research of CDs on the synthetic routes, chemical modifications, optical properties and biomedical applications. We will mainly discuss their applications in bioimaging of normal and cancer stem cells and tumour cells, two-photon fluorescence imaging, in vivo imaging, biosensing, and cancer therapy including photothermal therapy, photodynamic therapy and chemotherapy. At the end, current challenges and future perspectives of CDs in biomedical applications will also be discussed. We hope that this review will provide valuable insights to inspire new discoveries on CDs and draw a roadmap towards a broader range of biomedical applications.
\end{abstract}

\section{Introduction}

Carbon dots (CDs) typically refer to a fascinating type of zerodimensional (OD) carbon nanomaterials with lateral sizes below $10 \mathrm{~nm}$ and a lattice spacing of 0.21 and $0.34 \mathrm{~nm}$ corresponding to the (100) and (002) lattice planes of graphite. ${ }^{1,2}$ Graphene quantum dots (GQDs) and carbon quantum dots (CQDs) are two classic types of CDs. GQDs are specially small graphene fragments consisting of single- or few-layer graphene sheets, while CQDs always possess obvious crystal lattices, demonstrating

College of Chemistry, Key Laboratory of Theoretical \& Computational Photochemistry, and Radiopharmaceuticals, Ministry of Education, Beijing Normal University, Beijing, 100875, China.E-mail: y.zhang@bnu.edu.cn, lzfan@bnu.edu.cn $\dagger$ These authors contributed equally to this work. intrinsic state luminescence and the quantum confinement effect. ${ }^{3}$ It has significant meaning to regulate the wavelength of photoluminescence (PL) through the control of the CQD size. ${ }^{4}$ The first discovery of fluorescent carbon nanoparticles could be traced to 2004 during the purification of single walled carbon nanotubes by Scrivens and co-workers. ${ }^{5}$ In 2006, these quantum-sized nanoparticles with intense photoluminescence in both solution and the solid state were first coined as "carbon dots" by Sun and co-workers. ${ }^{6}$ Since then, considerable attention has been focused on the biomedical applications of CDs due to their low cytotoxicity, high water solubility, favorable biocompatibility, good photostability, high sensitivity and selectivity for target analytes, tunable fluorescence emission and excitation, high quantum yields, and relatively large Stokes shifts. ${ }^{7,8}$ Furthermore, the intriguing properties of CDs allow

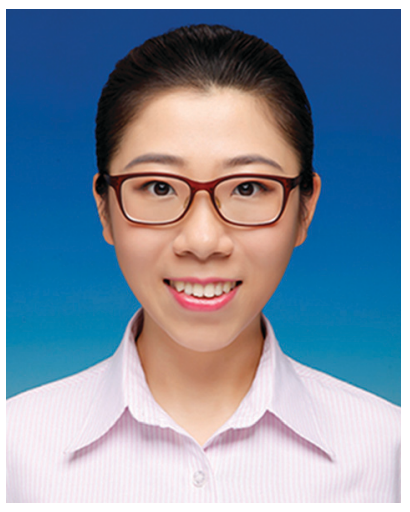

Wen Su received her Master's degree in analytical chemistry from Beijing Normal University in 2017. Currently, she is a PhD student under the supervision of Prof. Louzhen Fan at Beijing Normal University. Her research interests focus on the synthesis and biomedical applications of fluorescent carbon nanomaterials.

Wen Su

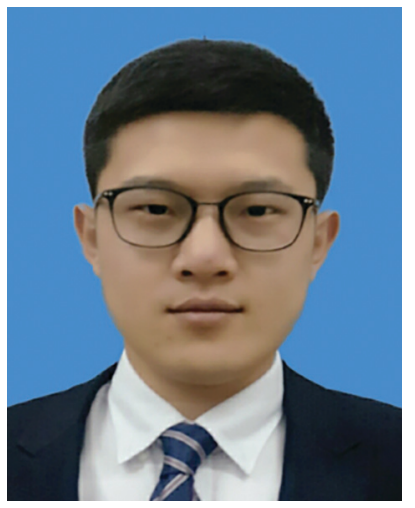

Hao Wu received his Master's degree in applied chemistry in 2018 at Northeast Agricultural University. After graduation, he continued to pursue his PhD under the supervision of Prof. Louzhen Fan at Beijing Normal University. His research interests focus on the synthesis and biomedical applications of carbon quantum dots. 
them to fulfill the crucial requirements of optical and photoelectronic devices, such as light-emitting diodes, photovoltaic devices and photodetectors. ${ }^{8-11} \mathrm{CDs}$, as a great candidate for bioimaging, exhibit broadband absorption and emission covering the deep ultraviolet, visible and near-infrared as well as efficient multi-photon up-conversion emission, which can be regulated by the surface functional species, size, shape and heteroatom doping. ${ }^{12-15}$ The high water solubility of CDs is a significant characteristic for materials in biological systems. CDs prepared by hydrothermal and solvothermal methods are functionalized with various types of surface groups, especially oxygen related carboxyl and hydroxyl groups, imparting excellent water solubility without further surface modification. ${ }^{16}$ The reactive groups at the rim of CDs greatly facilitate facile surface passivation and functionalization, which makes them suitable for drug delivery.

The optical and surface chemical properties of CDs make them promising candidates for theranostic applications, such as bioimaging, ${ }^{17}$ biosensing, ${ }^{18}$ and drug delivery, both in vitro and in vivo. ${ }^{19,20}$ In diagnostics, the fluorescence molecular bioimaging technique plays a vital role in tumour detection at early stages, which allows the noninvasive, highly sensitive and special observation of pathological and physiological events. $^{21}$ In comparison to existing imaging materials, such as semiconductor quantum dots (QDs), organic dyes and fluorescent proteins, CDs have the advantages of low cytotoxicity, excellent biocompatibility, stable photoluminescence, facile functionalization and remarkable resistance to photobleaching. ${ }^{22,23}$ On the basis of the abovementioned benefits of CDs, various bioimaging applications in vivo and in vitro have been recently developed. ${ }^{24-30}$ In addition, driven by the high sensitivity, low-cost and utility, CDs have been extensively applied in the development of next-generation optical biosensors for not only elemental and biomarker analysis but also at the single cell level through monitoring the change of the fluorescence signals, termed as fluorescence enhancement (turn-on) or fluorescence quenching (off-state). ${ }^{31-33}$ Surface and/or edge modification of CDs is one of the applicable strategies for achieving targeted ability in photodynamic therapy (PDT), photothermal therapy (PTT) and chemotherapy. ${ }^{20,34-36}$ Effective and low-cost surface modification would be fundamental to future clinical translation of the current targeting technology. ${ }^{36-39}$

There have been already some reviews focusing on different aspects of CDs, such as their synthesis, surface functionalization, PL properties and biological applications. ${ }^{21,22,40,41}$ In this review, we will provide an update on the recent developments in the synthesis, optical properties, and biological applications of CDs. Following that, bioimaging of normal and cancer stem

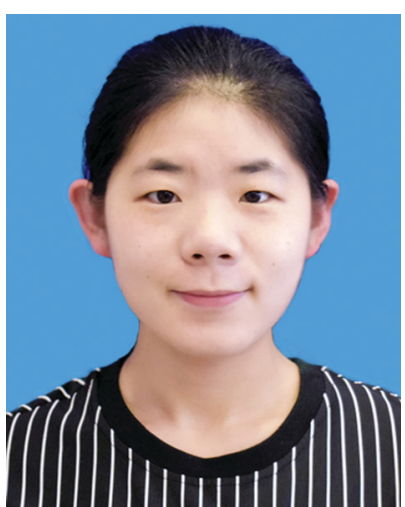

Huimin Xu
Huimin Xu obtained her BS degree in Chemistry from Shanxi Normal University in 2019. Now, she is a Master's student under the supervision of Prof. Louzhen Fan at Beijing Normal University. Her research interests focus on the synthesis and biomedical applications of carbon quantum dots.

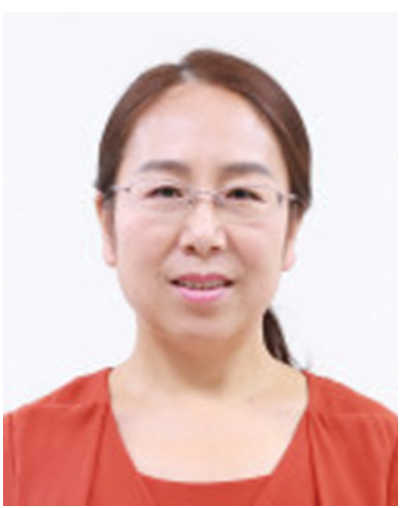

Xiaohong $\mathbf{L i}$
Xiaohong Li is now a chemistry professor of Department of Chemistry, Beijing Normal University. She received her $P h D$ in physical chemistry in 2004 under the supervision of Prof. Yongfang $\mathrm{Li}$ from Institute of Chemistry, the Chinese Academy of Sciences, Beijing. Her research interests are focused on biosensors for environmental pollutants.

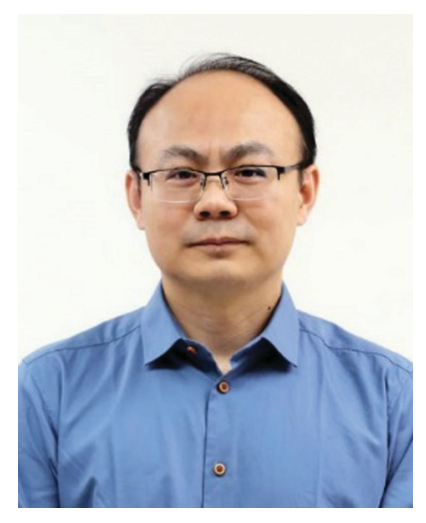

Yunchao Li
Yunchao Li is now a chemistry professor of Department of Chemistry, Beijing Normal University. He received his $P h D$ in physical chemistry in 2005 under the supervision of Prof. Yongfang $\mathrm{Li}$ from Institute of Chemistry, the Chinese Academy of Sciences, Beijing. His research interests are focused on the synthesis of new nanomaterials and design of new biosensors.

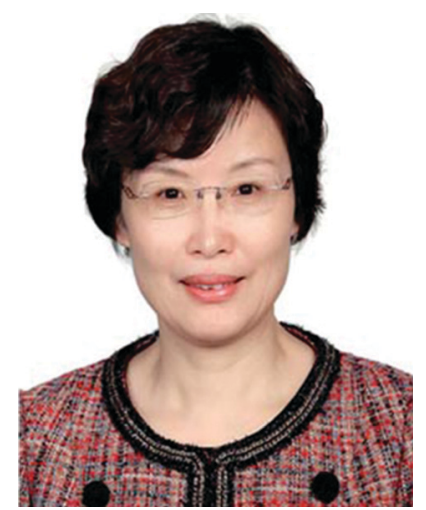

Louzhen Fan
Louzhen Fan is now a chemistry professor of Department of Chemistry, Beijing Normal University. She received her $P h D$ in physical chemistry in 1998 under the supervision of Prof. Daoben Zhu and Prof. Yongfang Li from Institute of Chemistry, the Chinese Academy of Sciences, Beijing. Her research interests are focused on the synthesis of novel carbon and metal nanomaterials and their applications in biology and energy. 


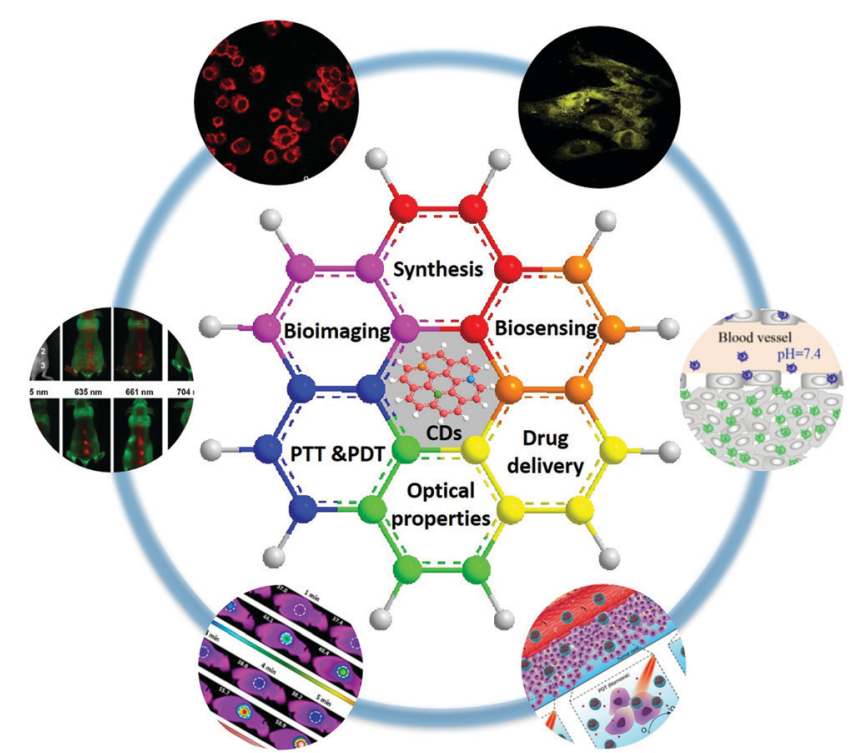

Fig. 1 Schematic illustration of the topic of this review, showing the recent trends in applications of CDs in biomedicine, including bioimaging, biosensing, and cancer therapy. Reprinted with permission from ref. 20, 53 , 54, 74, 82 and 143. Copyright 2017 American Chemical Society. Copyright 2012 and 2018 John Wiley and Sons. Copyright 2012 and 2017 Royal Society of Chemistry. Copyright 2016 Springer.

cells and tumour cells, two-photon (TP) fluorescence imaging and in vivo imaging, biosensing, and cancer therapy including PTT, PDT and chemotherapy (Fig. 1) will be discussed in detail. By comprehensively understanding the structure-function relationships of CDs, the present state and development prospects of CDs in biomedical applications are proposed.

\section{Preparation of CDs}

In 2004, fluorescent carbon nanoparticles were first isolated by Scrivens et al. through the purification of single-walled carbon nanotubes. ${ }^{5}$ Since then, various synthetic methods have been developed for the preparation of CDs with different size and surface functional groups. Typically, CDs can be synthesized by either top-down or bottom-up approaches. They are based on cutting the graphite matrix into nanosized particles and the chemical fusion of small aromatic molecules, respectively. For the applications of CDs in optoelectronic devices, the bottom-up approach is commonly regarded as a suitable method for synthesizing bandgap fluorescent CDs. ${ }^{42,43}$ As for biological applications, both methods are widely used for the preparation of CDs. Particularly, the top-down method can facilely deliver good water-soluble CDs for biological applications. The topdown method involves oxidative cleavage, ${ }^{44}$ reductive cutting, ${ }^{45}$ physical grinding, ${ }^{46}$ laser ablation, ${ }^{6,47}$ electrochemical oxidation ${ }^{48}$ and hydrothermal cutting, ${ }^{49}$ making it possible to obtain CDs from a wide range of carbon materials, such as graphite, ${ }^{50}$ graphene oxide, ${ }^{51}$ and carbon nanotubes. ${ }^{52}$ Our laboratory, for the first time, prepared water-soluble, uniform sized GQDs that can directly and easily penetrate into stem cells without affecting their viability, proliferation or differentiation capacity by electrochemical exfoliation of graphite followed by hydrazine reduction at room temperature. ${ }^{53}$ Lately, a novel imaging probe, pH-responsive fluorescent graphene quantum dots (pRF-GQDs), was prepared by electrolysis of graphite rods in sodium $p$-toluenesulfonate acetonitrile solution. The resulting pRF-GQDs with minimal toxicity exhibited a sharp fluorescence transition between green and blue at $\mathrm{pH}$ 6.8, a pH matching the acidic extracellular microenvironment in solid tumours. We found that this unique fluorescence switching property allows distinguishing tumours from normal tissues. ${ }^{54}$ The top-down methods have the advantages of abundant starting materials and simple operation. Moreover, the GQDs prepared via top-down methods usually contain functional groups at the edges of the GQDs, thus facilitating the subsequent modification of the GQDs. ${ }^{55}$ Nevertheless, the bottom-up methods offer the opportunity to control CDs with well-defined size, shape, and stable properties through the selection of the precursors and modulation of the synthetic conditions. Previous work reported that CDs can be prepared by step-wise solution chemistry of organic molecules, ${ }^{56}$ polymerization, ${ }^{57}$ fullerene cage opening and carbonizing some special organic precursors. ${ }^{58}$ Beyond that, renewable biomass carbon sources were developed as a sort of raw materials for the preparation of CDs. ${ }^{59,60}$ Our laboratory reported GQDs synthesized by pyrolysis of citric acid (CA) at $200{ }^{\circ} \mathrm{C}$ for $20 \mathrm{~min}$ and subsequent functionalization with carboxyl groups via conjugation of acetic acid moieties. Such GQDs possessed exceptionally high loading capacity for IR780 (an effective theranostic agent) via $\pi-\pi$ stacking interactions, while the hydrophilic carboxyl groups around the edge of the GQDs could covalently conjugate folic acid (FA) to enhance the tumour-targeting ability and avoid photodamage to surrounding normal tissues during PTT (Fig. 2a). ${ }^{20}$ The transmission electron micrograph (TEM) and high-resolution TEM (HRTEM) image indicated that most of the GQDs exhibited uniform atomic

a

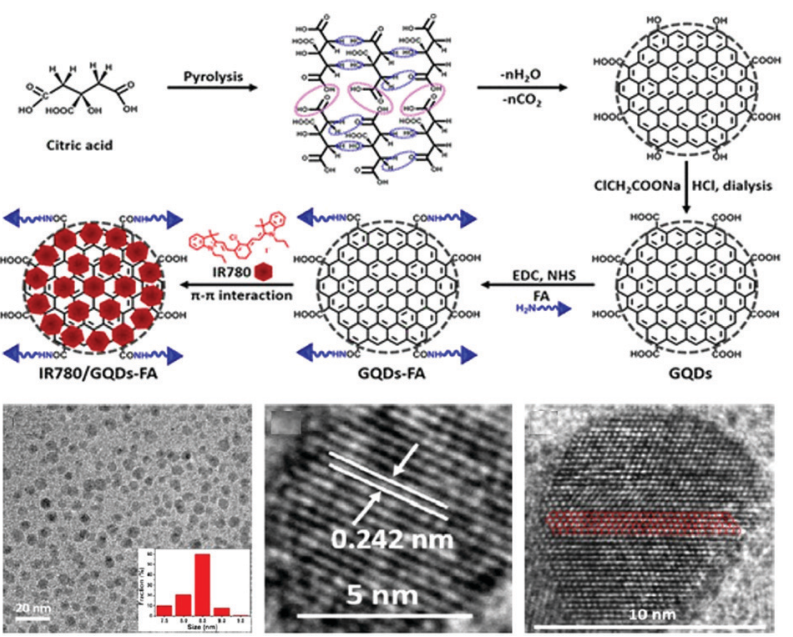

Fig. 2 (a) Schematic illustrating the preparation of IR780/GQD-FA. Reprinted with permission from ref. 20. Copyright 2017 American Chemical Society. (b) TEM image and HRTEM image with the measured lattice spacing and the $\mathrm{sp}^{2}$ domain of the GQDs. Reprinted with permission from ref. 20. Copyright 2017 American Chemical Society. 
arrangements with a high degree of crystallinity. The carbon hexagon structures were arranged orderly and the well-crystallized carbon areas almost occupied the whole dot, demonstrating that GQDs may consist of a large and intact $\mathrm{sp}^{2}$-domain (Fig. 2b). Wu et al. synthesized GQDs with NIR fluorescence emission in the range $800-850 \mathrm{~nm}$ by the facile pyrolysis of L-glutamic acid. ${ }^{60}$ The as-prepared GQDs possessed strong excitation-dependent photoluminescence with a high quantum yield (QY: $54.5 \%$ ) in solution, which were developed for biosensing and in vitro and in vivo bioimaging.

In order to broaden the applications of CDs, further chemical modifications are required. Many applications of CDs depend on effective strategies to conjugate specific materials onto the surface of CDs. In principle, CDs can be chemically stable and biocompatible after the attachment of biomolecules and drugs.

Polyethylene glycol (PEG) and polyethylenimine (PEI) are two of the most commonly used reagents for surface passivation of CDs due to their great biocompatibility and resistance to nonspecific binding, which always show stronger PL emission and offer a vital intermediate for further modification. ${ }^{61}$ Recently, Shen et al. reported the preparation of PEG-modified GQDs by the connection of carboxyl groups of GQDs and hydroxyl groups of PEG via a facile one-pot hydrothermal approach. ${ }^{62}$ It should be noted that the as-prepared GQDs exhibited strong blue PL emission under an $808 \mathrm{~nm}$ laser, which functioned as a new type of upconversion fluorescence material for applications in bioscience. As reported by Wang et al., PEI-functionalized GQDs (PEI-GQDs) were synthesized from used coffee grounds as a raw material. ${ }^{63}$ The hydroxyl groups on the surface of the GQDs were replaced by PEI through a low-temperature hydrothermal route. The as-obtained PEI-GQDs revealed an efficient fluorescence property and low cytotoxicity in applications of bioimaging and sensing of heavy metals. Moreover, the attachment of multiple ligands (such as antibodies, peptides, proteins, and nucleic acids) to the surface of CDs can be designed for site-specific delivery, and fluorescence targeting, tracking, and imaging both in vitro and in vivo. For instance, Lee and coworkers presented a microwave irradiation technique for the synthesis of thiol-terminated CDs from glycerol (SH-g CDs), applied for conjugation with maleimide-attached targeting molecules, which can specially bind to glioma and cervical cancer cells for targeting cancers. The SH-g CD labeled aptamer will provide a useful targeting imaging probe for various cancers and diseases. ${ }^{64}$ Folate receptor (FR) can be used as a target for monitoring overexpressed molecules in cancer cells. Among targeting ligands, FA possesses high affinity toward FR. $^{65}$ The targeting of cancer cells through detecting FR has attracted great attention. More recently, our laboratory reported the synthesis of FA functionalized GQDs, covalently conjugating FA by a 1-ethyl-3-(3-dimethylaminopropyl)carbodiimide/ $N$-hydroxy-succinimide condensation reaction to enhance the tumour targeting ability and photothermal conversion efficiency. ${ }^{20}$ The results indicated that the conjugates offered new perspectives for imaging early diagnosis and monitoring of cancers.

\section{Optical properties}

Typically, CDs show characteristic optical absorption in the UV-region (230 to $320 \mathrm{~nm}$ ) with a tail extending into the visible range due to the light absorption by the $\pi$-conjugated electrons in the $\mathrm{sp}^{2}$ atomic framework and the functional groups connected at the edge. The broad peak at $\sim 230 \mathrm{~nm}$ is ascribed to the $\pi-\pi^{*}$ transition of aromatic $\mathrm{C}=\mathrm{C}$ bonds, whereas the shoulder at $300 \mathrm{~nm}$ is attributed to the $\mathrm{n}-\pi^{*}$ transition of $\mathrm{C}=\mathrm{O}$ bonds or other connected groups. ${ }^{40,66}$ The absorption characteristics of CDs are mainly influenced by the size of $\pi$-domains, shape, composition and surface functional groups.

Multicolored luminescent CDs have been synthesized with different approaches, ranging from deep ultraviolet to red or even NIR absorption and emission. ${ }^{67,68}$ As the particle size increased, CDs demonstrated red-shifted absorption bands from blue to red fluorescence, no matter how broad or narrow the absorption. ${ }^{42,69}$ Our laboratory reported the first demonstration of bright multicolor bandgap fluorescent CQDs (MCBF-CQDs) from blue to red with a QY up to $75 \%$ for blue fluorescence. ${ }^{42}$ These MCBF-CQDs exhibited strong excitonic absorption bands in the UV-vis absorption spectra (Fig. 3a) centered at about 350, 390, 415, 480, and $500 \mathrm{~nm}$ for blue (B-), green (G-), yellow (Y-), orange (O-), and red BF-CQDs (R-BF-CQDs), respectively. As shown in Fig. 3b, the fluorescence peaks of the MCBF-CQDs were centered at about 430 (B-), 513 (G-), 535 (Y-), 565 (O-), and $604 \mathrm{~nm}$ (R-BF-CQDs), respectively. The red shifted fluorescence colors from blue to red are consistent with the redshifted excitonic absorption bands, indicating the band-edge nature of the optical transitions in the MCBF-CQDs. TEM characterization revealed that all of the five BF-CQDs demonstrated uniform and narrowly distributed nanoparticles with average sizes of about 1.95 (B-), 2.41 (G-), 3.78 (Y-), $4.90(\mathrm{O}-)$, and $6.68 \mathrm{~nm}$ (R-BF-CQDs). Recently, our laboratory reported high color-purity, narrow excitonic absorption and emission peak and multicolored (from blue to red) emission triangular CQDS (T-CQDs) with a QY up to $54-72 \% .{ }^{69}$ Fig. 3c presents the absorption spectra of the narrow bandwidth emission T-CQDs (NBE-T-CQDs) with strong and narrow excitonic absorption peaks centered at 460 (B-), 498 (G-), 521 (Y-), and 582 nm (R-NBE-T-CQDs), which were quite different from those of previously reported CQDs with ultrabroad absorption bands. ${ }^{7-18,23,26}$ The fluorescence spectra of the NBE-T-CQDs (Fig. 3d) also unveiled sharp excitonic emission peaks centered at 472 (B-), 507 (G-), 538 (Y-), and $598 \mathrm{~nm}$ (R-NBE-T-CQDs) with extremely narrow full width at half maximum (FWHM) values of only 30, 29, 30, and $30 \mathrm{~nm}$, respectively. Bright multicolored emission of blue, green, yellow, and red was observed from each NBET-CQD solution with gradually increasing sizes from $1.9 \mathrm{~nm}$ to $2.4,3.0$, and $3.9 \mathrm{~nm}$, respectively, which can be explained by the quantum confinement effect. ${ }^{7,16-18}$ Apart from the influence of the particle size, surface engineering, such as changing the surface state or functional groups, may also induce an absorption and emission wavelength red shift. In 2018, Qu et al. reported the red-shifted emission of CDs with increasing surface oxidation. ${ }^{70}$ The major absorption band of the CDs in $\mathrm{H}_{2} \mathrm{O}$ occurs at a wavelength of 

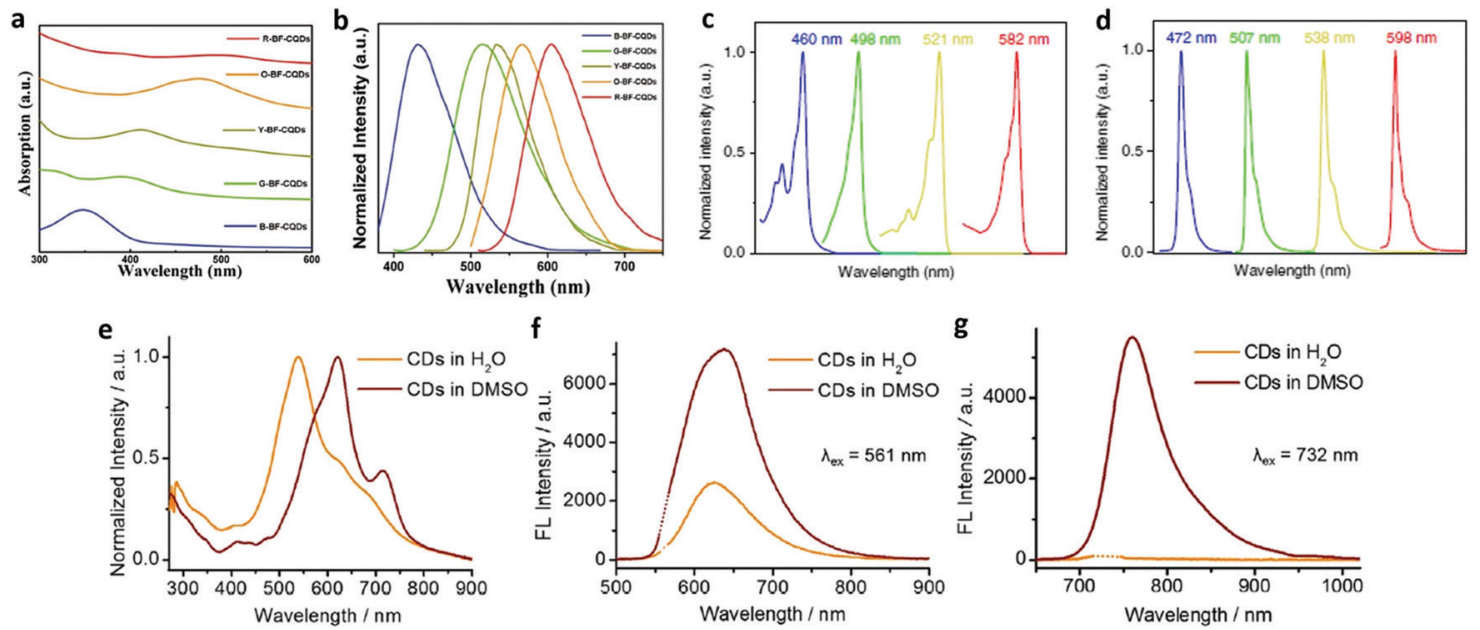

Fig. 3 (a) UV-vis absorption and (b) normalized fluorescence of B-BF-CQDs, G-BF-CQDs, Y-BF-CQDs, O-BF-CQDs, and R-BF-CQDs. Reprinted with permission from ref. 42. Copyright 2016 John Wiley and Sons. The normalized UV-vis absorption (c) and PL (d) spectra of B-, G-, Y-, and R-NBE-T-CQDs, respectively. Reprinted with permission from ref. 69. Copyright 2018 Springer. (e) Absorption spectra of CDs in $\mathrm{H}_{2} \mathrm{O}$ and DMSO. Fluorescence spectra of $\mathrm{CDs}$ in $\mathrm{H}_{2} \mathrm{O}$ (f) and DMSO (g) under excitation with a 561 and $732 \mathrm{~nm}$ laser. Reprinted with permission from ref. 70 . Copyright 2018 John Wiley and Sons.

$540 \mathrm{~nm}$ with a long tail extending into the NIR region (Fig. 3e, yellow line). In contrast, the CDs in dimethyl sulfoxide (DMSO) exhibit a redshifted main absorption band at $619 \mathrm{~nm}$, and an additional NIR absorption peak at $715 \mathrm{~nm}$ (Fig. 3e, red line). Under excitation at $561 \mathrm{~nm}$, the emission of the CDs in $\mathrm{H}_{2} \mathrm{O}$ occurred in the red region $\left(\lambda_{\max }=624 \mathrm{~nm}\right)$ with a PL QY of $6 \%$ and there was enhanced red fluorescence with a PL QY of $26 \%$ $\left(\lambda_{\mathrm{em}}=640 \mathrm{~nm}\right)$ in DMSO (Fig. 3f). Similarly, under excitation at $732 \mathrm{~nm}$ (Fig. 3g), owing to the NIR absorption band, these CDs also exhibited efficient NIR emission at $760 \mathrm{~nm}$ with a PL QY of $10 \%$ in DMSO but very weak NIR emission at about $760 \mathrm{~nm}$ in $\mathrm{H}_{2} \mathrm{O}$. The as-synthesized CDs demonstrated NIR absorption and enhanced NIR fluorescence of CDs through surface engineering. Recently, our laboratory reported efficient red emission electron-donating group passivated CQDs at 637, 642 , and $645 \mathrm{~nm}$, respectively. ${ }^{71}$ The preparation of full-color light-emitting CDs was reported, which exhibited excitationindependent behaviors. ${ }^{13}$ Their comparative studies revealed the relationship between the degree of surface oxidation of the CDs and their PL red shifts, excluding quantum size effects.

For biological applications, the following optical properties are quite important. CDs with long-wavelength excitation/absorption and emission can be considered a good candidate for not only bioimaging but cancer therapy as well. Compared with a higherenergy photon, a lower-energy photon with a longer wavelength has been shown to penetrate deeper into the sample. Therefore, red and infrared radiation in the tissue transparency window can penetrate more deeply through tissue and minimize photodamage in comparison with short wavelength excitation light. ${ }^{72}$ And TP excitation penetrates more deeply into the tissue than single-photon excitation. ${ }^{15,73}$ Far-red and NIR emissive CDs have made great advances due to the low interference from autofluorescence with the tissues, minimum tissue absorption, and deep tissue penetration in comparison with fluorescence imaging in the visible light region. ${ }^{74,75}$ Moreover, bandgap fluorescent CDs, whose maximum excitation wavelength agrees well with the corresponding excitonic absorption peak, have make a great contribution to high QY, which is convenient for observation.

\section{Biomedical applications of CDs}

Assessing the biocompatibility of CDs before considering their biological application is important for any further advancement, which includes in vitro and in vivo tests. The in vitro toxicity is also known as the cytotoxicity while in vivo tests choose the whole organism as a research object. Until now, researchers have evaluated the in vitro cytotoxicity of various CDs. Typically, in vitro cytotoxicity experiments involve cellular viability experiments via certain assays such as MTT, CCK8, WST-1, etc. Table 1 presents a summary of in vitro cytotoxicity studies of CDs. Generally, CDs are acknowledged to be a nanomaterial with low cytotoxicity. The in vivo toxicity of CDs is usually observed after injection of CDs. To date, there are few studies about the in vivo toxicity of CDs with different injection doses. In 2018, Wang et al. investigated the biosafety of HBCDs in mice. ${ }^{76}$ They studied in vivo imaging of tumors and major organs at different time points post-i.v. injection of HBCDs. Compared with the control group without any treatment, no evident histological alterations were observed. Their results illustrated the low side effects and excellent biocompatibility of HBCDs in vivo. The body weights of mice were recorded during different treatments with HBCDs and no sudden change was found, indicating the low biotoxicity of HBCDs for in vivo treatment. Recently, some researchers studied the distribution of CDs in mice after injection. In 2019, Singh et al. investigated the in vivo toxicity of nitrogen doped CQDs (NCQDs). ${ }^{77}$ In vivo toxic effects were evaluated for 30 days in Swiss albino mice at two different concentrations $(5.0 \mathrm{mg}$ per $\mathrm{kg}$ body weight (BW) 
Table 1 Summary of in vitro cytotoxicity studies of CDs

\begin{tabular}{|c|c|c|c|c|c|}
\hline CD type & Cell model & Assays & Incubation time $[\mathrm{h}]$ & Toxicity & Ref. \\
\hline GQDs & HeLa & MTT & 24 & $90 \%$ viability at $1000 \mu \mathrm{g} \mathrm{mL}{ }^{-1}$ & 87 \\
\hline S-GQDs & HeLa & MTT & 72 & $>95 \%$ viability at $1000 \mu \mathrm{g} \mathrm{mL}^{-1}$ & 88 \\
\hline N-GQDs & HeLa & CCK-8 & 24 & $96 \%$ viability at $200 \mu \mathrm{g} \mathrm{\textrm {mL } ^ { - 1 }}$ & 89 \\
\hline BN-GQDs & HeLa & CCK-8 & 24 & $90 \%$ viability at $400 \mu \mathrm{g} \mathrm{mL}{ }^{-1}$ & 90 \\
\hline \multirow[t]{2}{*}{ GQDs } & HeLa & WST-1 & 24 & $95 \%$ viability at $200 \mu \mathrm{g} \mathrm{mL}^{-1}$ & 91 \\
\hline & A549 & & & $85 \%$ viability at $640 \mu \mathrm{g} \mathrm{mL}{ }^{-1}$ & \\
\hline g-CNQDs & U251 cells & MTT & 24 & $92 \%$ viability at $300 \mu \mathrm{g} \mathrm{mL}^{-1}$ & 92 \\
\hline pRF-GQDs & HeLa, MCF-7 & CCK-8 & 24 & $>90 \%$ viability at $100 \mu \mathrm{g} \mathrm{mL}^{-1}$ & 54 \\
\hline IR780/GQD-FA & HeLa & CCK-8 & 12 & $>90 \%$ viability at $30 \mu \mathrm{g} \mathrm{mL}^{-1}$ & 20 \\
\hline (GQD/DBM)3EuPhen/GQD & MCF-7 & MTT & 24 & $>90 \%$ viability at $100 \mu \mathrm{g} \mathrm{mL}^{-1}$ & 82 \\
\hline RF-GQDs & HeLa & MTT & 24 & $>85 \%$ viability at $1000 \mu \mathrm{g} \mathrm{mL}^{-1}$ & 93 \\
\hline GQDs & NSCs, CPCs & MTT & 72 & $>80 \%$ viability at $100 \mu \mathrm{g} \mathrm{mL}^{-1}$ & 53 \\
\hline CD-Asp & C6 glioma & MTT & 48 & $>90 \%$ viability at $200 \mu \mathrm{g} \mathrm{mL}^{-1}$ & 94 \\
\hline N-GQDs & HeLa & MTS & 24 & $83 \%$ viability at $1000 \mu \mathrm{g} \mathrm{mL}^{-1}$ & 95 \\
\hline N-GQDs & HeLa & MTT & 24 & $>85 \%$ viability at $100 \mu \mathrm{g} \mathrm{mL}^{-1}$ & 96 \\
\hline FA-GdN@CQD-MWCNT & MCF-7 & MTT & 24 & $>90 \%$ viability at $600 \mu \mathrm{g} \mathrm{mL}^{-1}$ & 97 \\
\hline $\mathrm{HFn} / \mathrm{CD}$ & MCF-7 & MTT & 48 & $>90 \%$ viability at $200 \mu \mathrm{g} \mathrm{mL}^{-1}$ & 98 \\
\hline
\end{tabular}

and $10.0 \mathrm{mg}$ per $\mathrm{kg} \mathrm{BW}$ ) of NCQDs. Their results of haematological, serum biochemical, antioxidant and histopathological parameters demonstrated that the NCQDs presented excellent biocompatibility. $^{77}$

Bioimaging techniques play a critical role in both fundamental research and clinical settings, allowing detailed observation of biological processes, ${ }^{78-80}$ which considerably facilitates the intuitive study of cell morphology and cell physiological processes. In cancer diagnostics, bioimaging is especially useful for the early detection of tumours and identification of metastasis as well as the resurgence of cancer. As a new class of bioimaging agents, CDs offer substantial advantages over inorganic semiconductor QDs and organic dyes in in vitro imaging owing to the unique combination of several key merits. ${ }^{81,82}$ Therefore, CDs have been regarded as a sensitive biological probe for both in vivo and in vitro imaging. ${ }^{81,83,84}$

\section{In vitro imaging}

Given the significance of cancer research, most of the CD-based studies focus on cancer cell imaging, which was first reported in $2011 .^{85,86}$ The work unveiled that GQDs with stable fluorescence emission hold promising potential in bioimaging. Since then, attempts have been made for cancer cell imaging with various CDs, such as of MCF-7 cells, ${ }^{99,100}$ T47D cells, ${ }^{101}$ and HeLa cells. ${ }^{93,102}$ CDs with TP emission are urgently needed in cancer cell imaging, owing to the avoidance of harmful UV or blue excitation and the reduction of photodamage in biotissues. ${ }^{15}$ A facile approach was reported for the preparation of highefficiency TP emission CDs with unique features of pure red emission $\left(\lambda_{\max } \approx 640 \mathrm{~nm}\right)$, high QY $(22.9 \%)$, low cytotoxicity, high photothermal conversion efficiency (43.9\% under irradiation with a $671 \mathrm{~nm}$ laser) and TP excited fluorescence. ${ }^{103}$ These red emissive CDs (R-CDs) were verified to be capable of TP fluorescence bioimaging in living cells (Fig. 4). As seen in TP mode, red emission from MCF-7 and HeLa cells can be observed under irradiation with an $850 \mathrm{~nm}$ fs pulse laser, clearly indicating the abilities of the R-CDs as TP bioimaging agents. Quantification of the fluorescence intensity profiles unveiled the stronger emission in the nucleoli regions, indicating that the R-CDs were
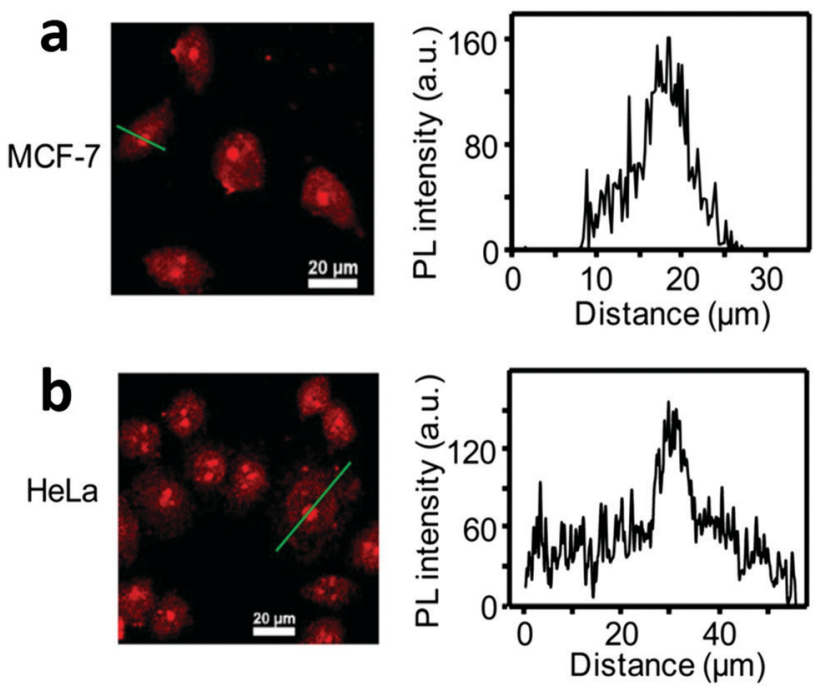

Fig. 4 TP confocal fluorescence images of (a) living MCF-7 cells and (b) living HeLa cells, and corresponding quantitative figure along the green line $\left(\lambda_{\mathrm{ex}}=850 \mathrm{~nm}\right.$ fs pulse laser, $\lambda_{\mathrm{em}}=600-700 \mathrm{~nm}$, scale bar $\left.=20 \mu \mathrm{m}\right)$. Reprinted with permission from ref. 103. Copyright 2016 American Chemical Society.

capable of nucleolus staining. Because of the nucleolus being an RNA-rich region, the observed nucleolus staining implies that the R-CDs have higher affinity to RNA than DNA and other substances in the cytoplasm. Besides, the TP absorption crosssection is an important evaluation parameter for evaluating the luminescence efficiency. Nitrogen-doped GQDs (N-GQDs) have been used as efficient TP fluorescent probes for HeLa cell imaging. ${ }^{104}$ The HeLa cells became illuminated when imaged under irradiation at $800 \mathrm{~nm}$. The TP absorption cross-section of the N-GQDs reached 48000 Göppert-Mayer units, which far surpassed that of organic dyes and was comparable to that of high-performance semiconductor QDs.

Stem cells are a class of multipotent cells with self-replication ability, which can give rise to tissue progenitor cells and in turn differentiate into tissue-forming cells. ${ }^{105-107}$ When stem cells or their progeny regenerate tissues and organs, there is a critical 

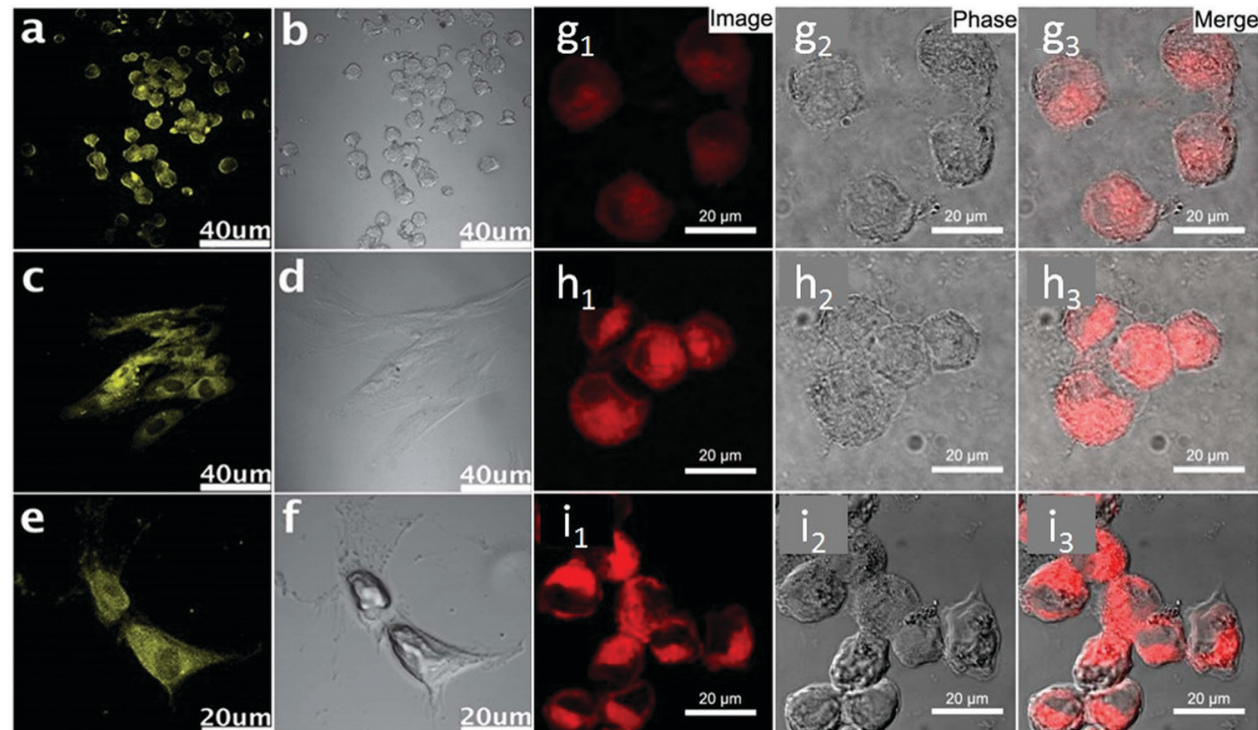

Fig. 5 Confocal fluorescence microscopy images of stem cells of NSCs (a), PPCs (c) and CPCs (e) with fluorescent GQDs incorporated at an excitation wavelength of $405 \mathrm{~nm}$ and the corresponding images under bright field (b, d and f). Reprinted with permission from ref. 53 . Copyright 2012 Royal Society of Chemistry. Confocal fluorescence microscopy images of pancreatic CSCs incubated with (g) $10 \mu \mathrm{M}$, (h) $25 \mu \mathrm{M}$ and (i) $50 \mu \mathrm{M}$ Fe ${ }^{3+}$ for 5 h, followed by further incubation with RBD-GQDs $\left(25 \mathrm{mg} \mathrm{L}^{-1}\right)$ for $0.5 \mathrm{~h}$. Reprinted with permission from ref. 117. Copyright 2015 American Chemical Society.

need to delineate the relative contribution to the regenerated tissues and organs from the delivered cells versus the host cells. Therefore, nontoxic and long-term stem cell imaging is urgently needed in the field of regenerative therapy for understanding their contribution to, migration to and fate in the regenerating tissues. ${ }^{102,108-112}$ We demonstrated the unique advantages of the GQDs mentioned above for highly efficient labeling of three different kinds of stem cells, including cardiac progenitor cells (CPCs), pancreas progenitor cells (PPCs) and neurospheres cells (NSCs), opening up great opportunities for their biomedical applications.

As shown in the confocal fluorescence images (Fig. 5a-f), the morphology of stem cells could be clearly discerned with the internalized GQDs. ${ }^{53}$ Even after being treated with GQDs, no significant changes were observed in the differentiation potential, metabolic activity, proliferation and viability of the cells. For illustrative purposes, we took two other fluorescent substances for comparison, including $\mathrm{C}_{60}$ nanoparticles and CdS QDs. Interestingly, the fluorescent $\mathrm{C}_{60}$ nanoparticles could not be internalized by stem cells, and could easily penetrate into cancer cells. ${ }^{113}$ In the case of CdS QDs, they were proved to be cytotoxic to stem cells. It was the first experimental observation of CDs as a fluorescent imaging agent in long-term stem cell imaging. The as-synthesized CDs are expected to have promising biomedical applications in comparison with previously reported carbon-based fluorescent nanomaterials, particularly in tracking differentiation of various cell lineages, apoptosis and proliferation, due to the scope for further straightforward functionalization. We further investigated the uptake mechanism and biocompatibility of such GQDs with human neural stem cells (hNSCs). ${ }^{107}$ It was confirmed that the GQDs were indeed internalized by the hNSCs via the endocytosis mechanism and were located in the cytoplasm. The GQDs did not affect the self-renewal and expression of the cell type-specific marker in hNSCs. Single cells dissociated from the GQD-labeled hNSCs formed large neurospheres after 12 days in normal culture medium and cells expressing the cell type-specific marker for hNSCs and nestin were identified.

As a subpopulation of stem-like cells, cancer stem cells (CSCs) exhibit the characteristics of both stem cells and cancer cells. ${ }^{114}$ They are capable of self-renewing inside a tumour and generating heterogeneous lineages of cancer cells, driving cancer progression, metastasis and drug resistance. ${ }^{115,116} \mathrm{CSCs}$ could cause tumour relapse due to their strong self-renewal ability, and are considered a possible new target of cancer therapies. CSC labeling poses considerable challenges due to their particularity. Our laboratory successfully synthesized Rhodamine B derivative-functionalized GQDs (RBD-GQDs) and firstly explored their feasibility as CSC imaging agents. ${ }^{117}$ As shown in Fig. 5g-i, the RBD-GQDs exhibited strong orange-red intracellular fluorescence, indicating that the RBD-GQDs could penetrate the pancreatic CSC membrane.

\section{In vivo imaging}

Apart from in vitro cell imaging, CDs are increasingly used for in vivo cell imaging and have provided fruitful results. In 2009, a study about the feasibility of CDs as a fluorescent contrast agent in mice was first carried out (Fig. 6). ${ }^{118}$ Afterwards, a variety of CDs have been synthesized and used for in vivo imaging. ${ }^{74,119,120}$ Excitation with longer wavelengths is highly preferred for in vivo imaging due to deeper light penetration into the specimens. However, most previously reported CDs emitted only blue to green fluorescence. CDs for in vivo imaging emitting in the red or NIR region are still challenging. Tumour selective imaging in vivo regardless of the origin and location but not in normal tissues is also a major task. Our laboratory reported IR780/GQD-FA with an emission peak at $800 \mathrm{~nm}$, 

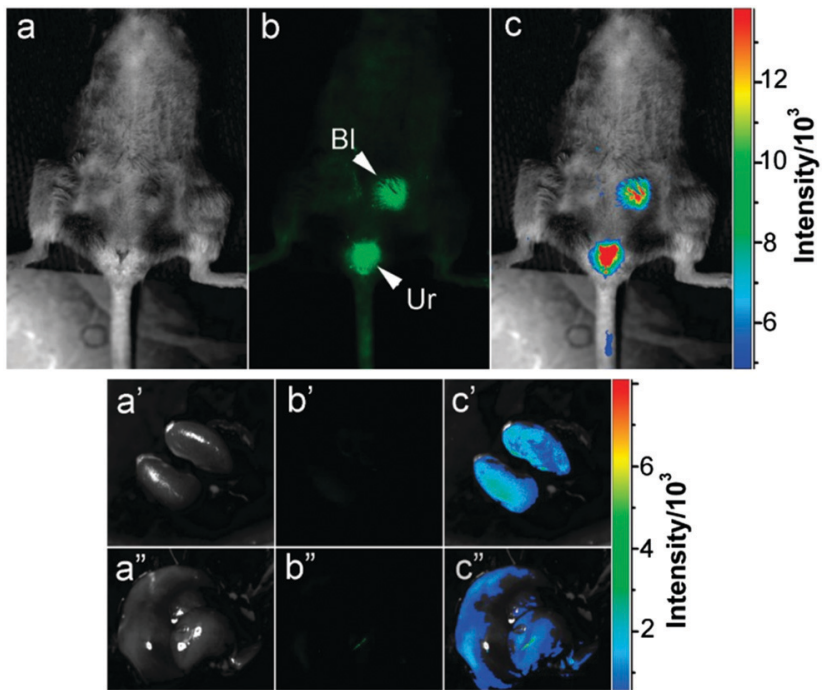

Fig. 6 Intravenous injection of CDs: (a) bright field, (b) as-detected fluorescence (Bl, bladder; Ur, urine), and (c) color-coded images. The same order is used for the images of the dissected kidneys $\left(a^{\prime}-c^{\prime}\right)$ and liver $\left(a^{\prime \prime}-c^{\prime \prime}\right)$. Reprinted with permission from ref. 118. Copyright 2009 American Chemical Society.

which also was successfully applied for in vivo fluorescence imaging by intravenous injection. ${ }^{20}$ Fig. 7 shows that the IR780/GQD-FA accumulated in the HeLa tumour area through folate-based active targeting and a significant fluorescence signal was observed in the tumour area in comparison with other tissues. The fluorescence intensity of IR780/GQD-FA accumulated in the tumour areas and peaked at $24 \mathrm{~h}$ postinjection. These are fluorescence imaging agents for cancer diagnosis in living systems. Mice were sacrificed $24 \mathrm{~h}$ postinjection, and the excised tumour exhibited strong fluorescence intensity, whereas the normal organs revealed very low signals, which was better than the in vivo behavior of many other previously reported CDs.

Although great progress in fluorescence imaging technique of CDs has been made in the past several years, the spatial resolution is still far from satisfactory in in vivo imaging. It is necessary to develop multi-modal imaging probes through incorporation of other imaging modalities, such as photoacoustic (PA) imaging and magnetic resonance imaging. ${ }^{121}$ Recently, PA imaging has emerged as a novel method that allows imaging beyond the optical diffusion limit by integrating optical excitation with ultrasonic detection based on the PA effect, providing deeper tissue-imaging penetration and higher spatial resolution. ${ }^{122}$ Fluorescence and PA images of the tumor area at different time points were observed in comparison with other tissues. During the entire imaging process, the PA signals were relatively constant with prolonged circulation in blood vessels, indicating that CDs can be considered a candidate for PA imaging.

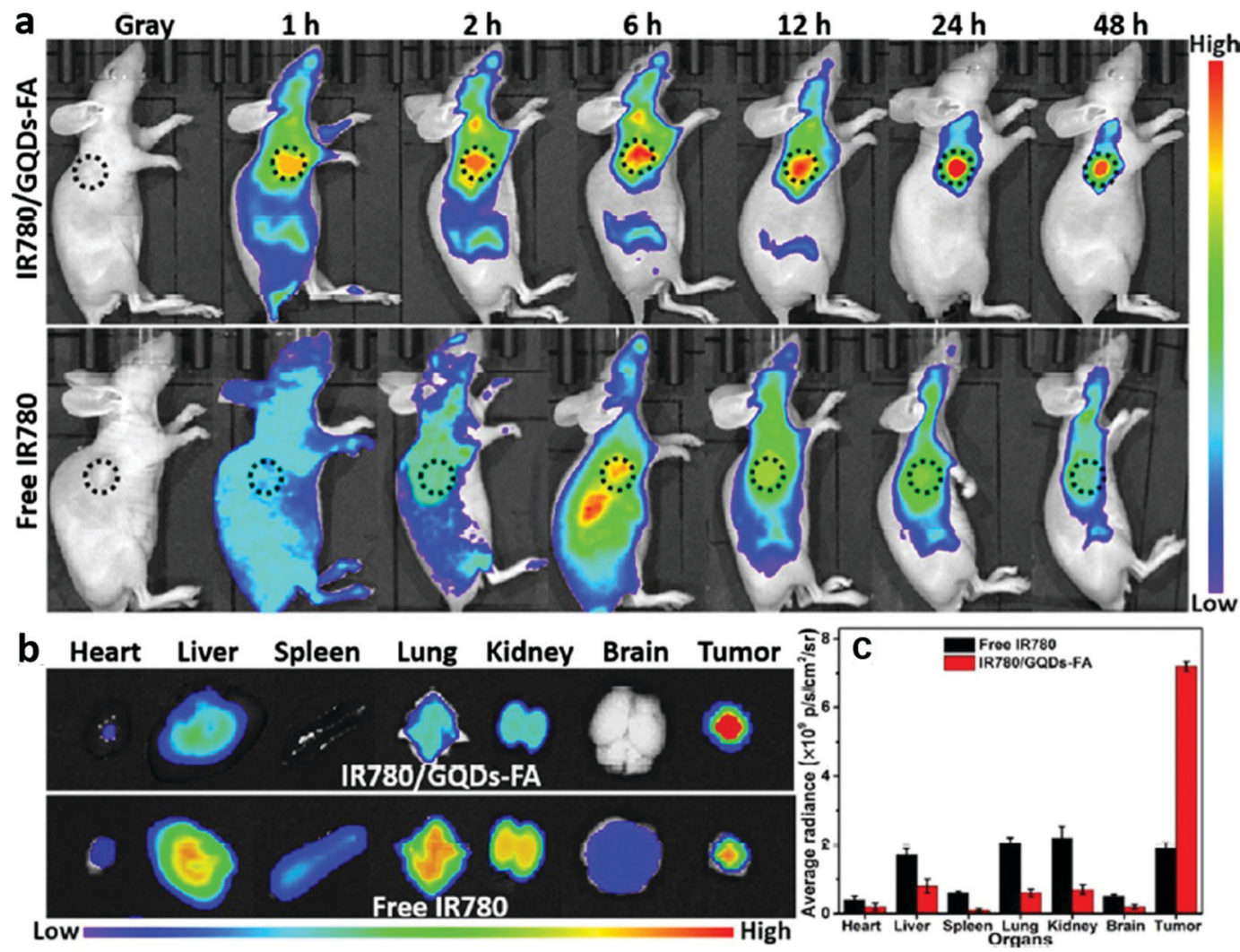

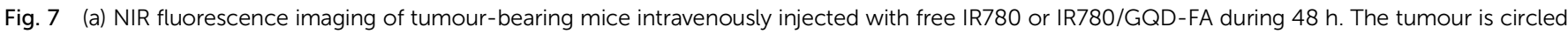

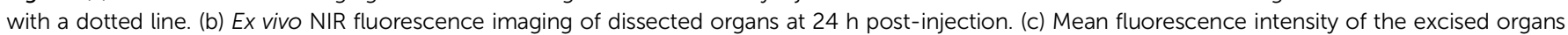

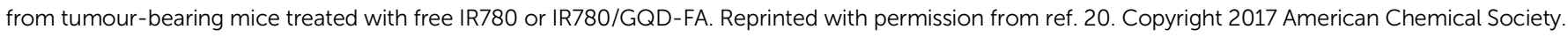



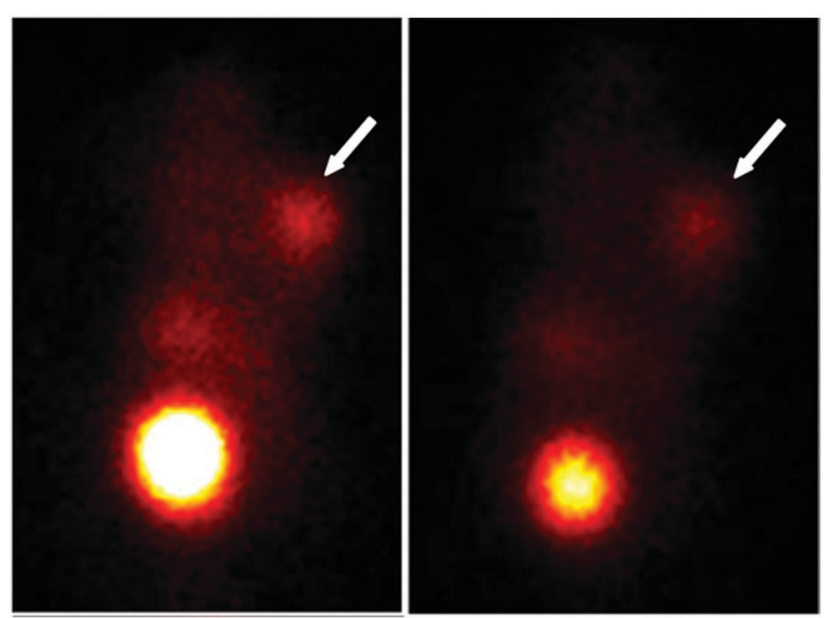

Fig. 8 SPECT images of ${ }^{131}$ I-GQD-PEG-FA in tumour bearing mice (the arrows point at tumour sites). Reprinted with permission from ref. 125. Copyright 2019 Springer.

For in vivo imaging study, the radioactive imaging technique of CDs represents one of the most meaningful approaches due to the excellent imaging effect of radionuclides. ${ }^{123,124}$ In 2019, PEG and FA co-functionalized GQDs were successfully synthesized to simultaneously improve the biocompatibility and tumourtargeting ability of GQDs, and labeled GQD-PEG-FA with ${ }^{131}$ I ( ${ }^{131}$ I-GQD-PEG-FA) for biological behavior evaluation. ${ }^{125}$ The single photon emission computed tomography (SPECT) imaging of ${ }^{131}$ I-GQD-PEG-FA was investigated while the uptake of ${ }^{131}$ I-GQD-PEG-FA at tumour sites could be clearly examined via SPECT imaging (Fig. 8). The $\mathrm{T} / \mathrm{B}$ and $\mathrm{T} / \mathrm{M}$ values of the ${ }^{131}$ I-GQD-PEG-FA in this work were as high as 2.67 and 6.27 at $24 \mathrm{~h}$ after injection, suggesting promising clinical application.

\section{Biosensing}

Biomolecular analysis plays an important role in clinical treatment security, food safety, environmental monitoring and disease diagnosis. ${ }^{126}$ Biosensors have been widely applied for analyzing small biological molecules, metal ions and proteins. In the past few years, inorganic semiconductor-based biosensors have been broadly investigated in numerous studies, exhibiting high fluorescence QY and photostability. ${ }^{127}$ However, they were found to cause health issues due to their heavy metal composition, which was unsuitable for in vivo applications. ${ }^{128,129}$ Recently, CD-based biosensors have received much attention. CDs have been demonstrated to exhibit excellent fluorescence performance with specific surface functional groups, which provide opportunities to connect with target analytes via various kinds of interactions such as electrostatic interactions, $\pi-\pi$ conjugation or electron transfer, resulting in fluorescence turn-on or turn-off effects of CDs. Moreover, CDs deliver excellent electrical conductivity, good dispersibility, and a large specific surface area, which are advantageous for biological molecule loading on their surface, rendering them excellent fluorescent probes for the detection of analytes of interest including inorganic ions and small molecules in biological samples. For instance, those RBD-GQDs were also used as an $\mathrm{Fe}^{3+}$ turn-on fluorescence sensor, with a detection limit of $0.02 \mu \mathrm{M}$
(Fig. 5g-i). ${ }^{117}$ The RBD-GQDs exhibited orange-red fluorescence, which was increased by the addition of $\mathrm{Fe}^{3+}$ ions due to the spirolactam ring of RBD being switched by $\mathrm{Fe}^{3+}$ ions. Further research demonstrated that the RBD-GQDs could penetrate the CSC membrane and be responsive to intracellular $\mathrm{Fe}^{3+}$ ions. In addition to the detection of metal ions, CDs can also be applied to the detection of other molecules. In 2015, a mitochondriatargetable nanoprobe based on triphenylphosphonium modified CDs with high sensitivity and selectivity was reported for peroxynitrite sensing in living cells. ${ }^{130}$ The fluorescence of the CDs was quenched in the presence of peroxynitrite due to the process of photoinduced electron transfer. Furthermore, this nanoprobe exhibits a universal and good mitochondria-targetable property towards many kinds of cancer cells. In 2016, Wang et al. reported a deliberately designed $\mathrm{ON}-\mathrm{OFF}-\mathrm{ON}$ fluorescent probe for the detection of glutathione (GSH) and temperature based on aggregationinduced fluorescence quenching and recovery, respectively. ${ }^{131}$ After adding GSH, the fluorescence of the CDs was then quenched strongly via the interaction between the surface groups and GSH, which led to the fluorescence switching to the OFF state. Increasing the temperature resulted in the destruction of this interaction and resulted in the fluorescence switching to the ON state. Furthermore, biosensing plays an indispensable role in the diagnosis and detection of cancer. Our laboratory proposed a new type of water-soluble, multicolor fluorescent GQDs which are responsive to all $\mathrm{pH}$ from 1 to 14 , observable with the naked eye. ${ }^{108}$ The fluorescence of the resulting GQDs was also found to be responsive to temperature changes, demonstrating great potential as a dual probe of $\mathrm{pH}$ and temperature in complicated environments such as biological media (Fig. 9a-f). As an acid microenvironment exists in solid tumours regardless of their origin, CDs which respond to $\mathrm{pH}$ could be ideal for tumour detection. Our laboratory proposed pRF-GQDs for the early detection of tumours in $2017,,^{54}$ which were prepared by electrolysis of graphite rods in sodium $p$-toluenesulfonate acetonitrile solution. As shown in Fig. $9 g$ and $h$, the pRF-GQDs exhibited a sharp fluorescence transition between green and blue at $\mathrm{pH} 6.8$, a $\mathrm{pH}$ matching the acidic extracellular microenvironment in solid tumours. Therefore, the pRF-GQDs had great potential to be used as a universal probe for fluorescence-guided cancer surgery and cancer diagnosis. Peng et al. made substantial contributions in the biosensing application of CDs. In 2018, they synthesized simultaneously hydrophilic and organophilic CDs by a facile one-pot solvothermal approach. The as-prepared CDs can be dissolved both in water and ethanol, exhibiting bright white and blue fluorescence under $365 \mathrm{~nm}$ UV illumination. Because the CDs exhibited high water solubility and good biocompatibility, they can be used for sensing $\mathrm{Au}^{3+}$ ions in aqueous solution and living cells, respectively. ${ }^{132}$ Other red emissive CDs were synthesized by using citric acid and neutral red as precursors, which demonstrated red fluorescence in both solution and the solid state. They were successfully applied for the detection of noble metal ions in PC12 cells and zebrafish. ${ }^{133}$

\section{Tumor therapy}

The development of safe and effective therapy methods plays a key role in cancer treatment, such as PDT, PTT and 

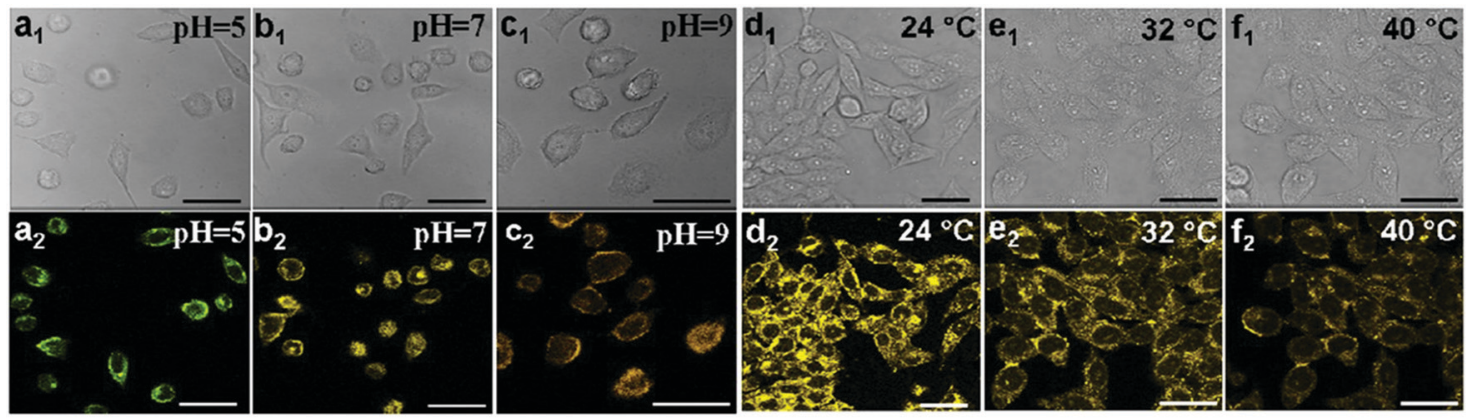

g

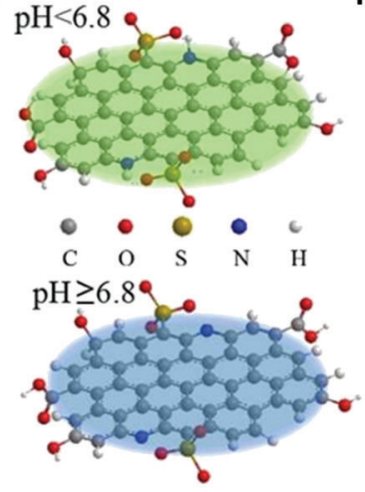

h

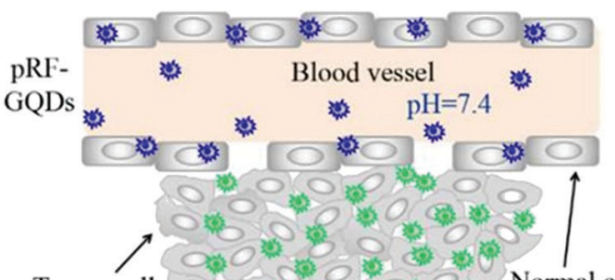

Tumor cells

$\mathrm{pH}<6,8$

Blue fluorescence in normal $\mathrm{pH}$

Green fluorescence in acidic $\mathrm{pH}$

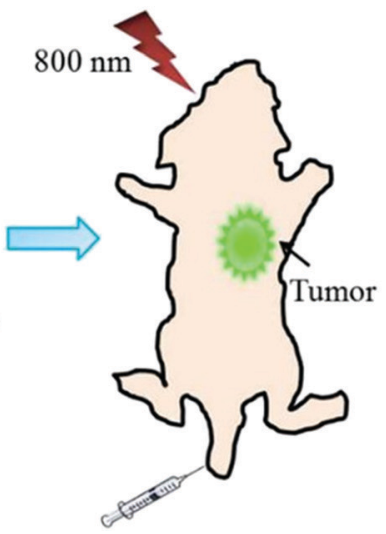

Fig. 9 Cell imaging of HeLa cells at predetermined $\mathrm{pH}$ and temperature conditions (excitation at $405 \mathrm{~nm}$ ). Bright field $\left(\mathrm{a}_{1}, \mathrm{~b}_{1}\right.$, and $\left.\mathrm{c}_{1}\right)$ and fluorescence field $\left(a_{2}, b_{2}\right.$, and $\left.c_{2}\right)$ of HeLa cells cultured at predetermined $\mathrm{pH}$ values. Bright field $\left(\mathrm{d}_{1}, \mathrm{e}_{1}\right.$, and $\left.\mathrm{f}_{1}\right)$ and fluorescence field $\left(\mathrm{d}_{2}, \mathrm{e}_{2}\right.$, and $\left.\mathrm{f}_{2}\right)$ imaging of HeLa cells at predetermined temperatures. Reprinted with permission from ref. 108. Copyright 2015 Royal Society of Chemistry. Schematic diagrams of pRF-GQDs at different $\mathrm{pH}$ values (g) and their application for tumour imaging (h). Reprinted with permission from ref. 54. Copyright 2017 Royal Society of Chemistry.
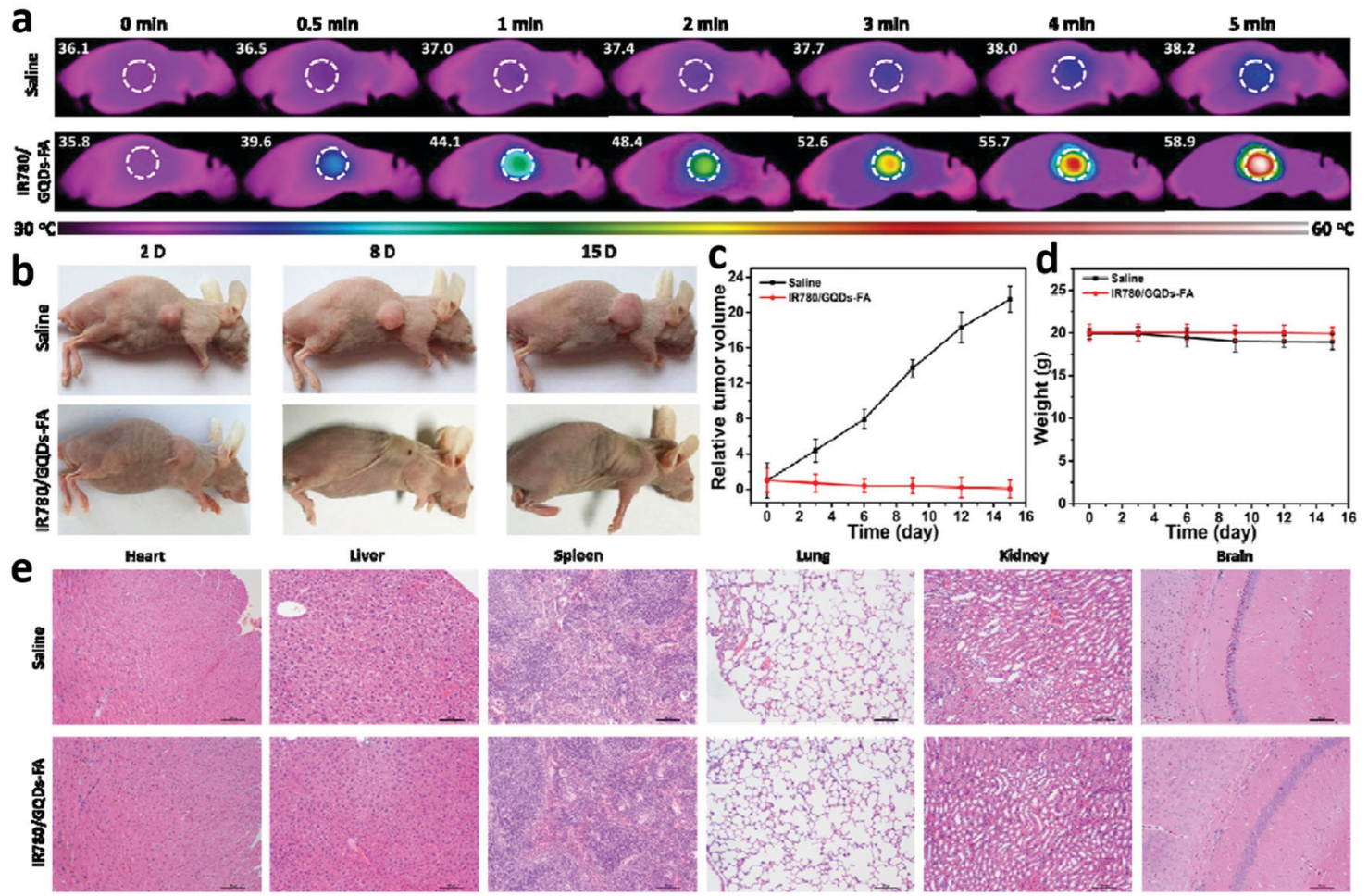

Fig. 10 (a) Thermal images showing the temperature variations of tumours after intravenous injection of saline or IR780/GQD-FA with laser irradiation. (b) Representative images of tumour bearing mice after treatment. Tumour volume (c) and body weight (d) curves of tumour-bearing mice from the different treatment groups. (e) Histological evaluation of tissues from mice treated with saline and IR780/GQD-FA. Each organ was sliced for H\&E staining. Reprinted with permission from ref. 20. Copyright 2017 American Chemical Society. 
targeted chemotherapy. CDs can be chemically conjugated with targeting ligands, enabling them to effectively target tumours. The presence of the $\pi$-plane in the CDs allows chemotherapeutic drugs, photosensitizers and other therapeutic agents with aromatic rings to be tightly bound to the $\pi$-plane of the CDs, further increasing the targeting efficiency and drug loading capacity.

A PTT agent delivery platform was successfully designed on the basis of CDs. The IR780/GQD-FA mentioned above was also used for PTT in live mice under NIR irradiation $(808 \mathrm{~nm})$ with a high photothermal conversion efficiency of $87.9 \% .^{20}$ As presented in Fig. 10a, after being intravenously injected with saline or IR780/GQD-FA for $24 \mathrm{~h}$, tumour-bearing nude mice were anesthetized and irradiated with an $808 \mathrm{~nm}$ laser for $5 \mathrm{~min}$. The IR thermographic results revealed that the local tumour temperature reached $58.9{ }^{\circ} \mathrm{C}$ in the presence of IR780/GQD-FA upon $808 \mathrm{~nm}$ laser illumination for $5 \mathrm{~min}$. As demonstrated in in vivo antitumour studies, IR780/GQD-FA in combination with laser irradiation exhibited obvious suppressive effects on tumour growth and the tumour almost disappears on day 15 , while the volume of the tumours increased greatly in the saline group (Fig. 10b and c). As shown in Fig. 10d, there was no significant decrease in body weight of the mice treated with IR780/GQD-FA, indicating that IR780/GQD-FA is non-toxic at the given dose, which was also confirmed by hematoxylin and eosin (H\&E) staining examination (Fig. 10e) and blood tests. In 2018, some heteroatom doped CDs were also used in PTT. Sulfur and nitrogen codoped NIR CDs were synthesized with intense absorption bands in the red to NIR region. ${ }^{134}$ The S, $\mathrm{N}$-codoped CDs possessed a high photothermal conversion efficiency of $59 \%$ due to their unique NIR absorption feature. After intravenous injection, the S,N-codoped CDs were accumulated in tumour tissue via passive targeting. According to the IR thermographic characterization, the temperature in the tumour area rapidly reached $59-71{ }^{\circ} \mathrm{C}$ in the presence of the CDs under laser irradiation (5 min) (Fig. 11a). However, the maximum temperature of the tumour area in the control group (with intravenous phosphate buffered saline (PBS) injected) was only approximately $44{ }^{\circ} \mathrm{C}$ under the same irradiation conditions (Fig. 11b), demonstrating that the S,N-codoped CDs played a key role in heat generation. The antitumour studies showed that the CDs in combination with laser irradiation unveiled obvious suppressive effects on tumour growth and the tumour almost disappeared on day 10 , while the volume of the tumours increased greatly in the PBS group (Fig. 11c). It should be mentioned that the mice in the PTT treatment group survived over 3 months without tumour reoccurrence, and the mice in the PBS group had an average life of 14-18 days (Fig. 11d). As shown in Fig. 11e, no significant signs of organ damage were observed in the PTT treatment group.

According to previous studies on the ability to efficiently generate reactive oxygen species (ROS), negligible drug resistance, low systemic toxicity, and flexible remote controllability and non-invasive procedures, PDT is considered to be a promising approach in cancer therapy. ${ }^{135,136}$ In recent research, tumour cells were killed by ROS produced by CDs in the presence of oxygen under irradiation. ${ }^{137,138}$ ROS production from
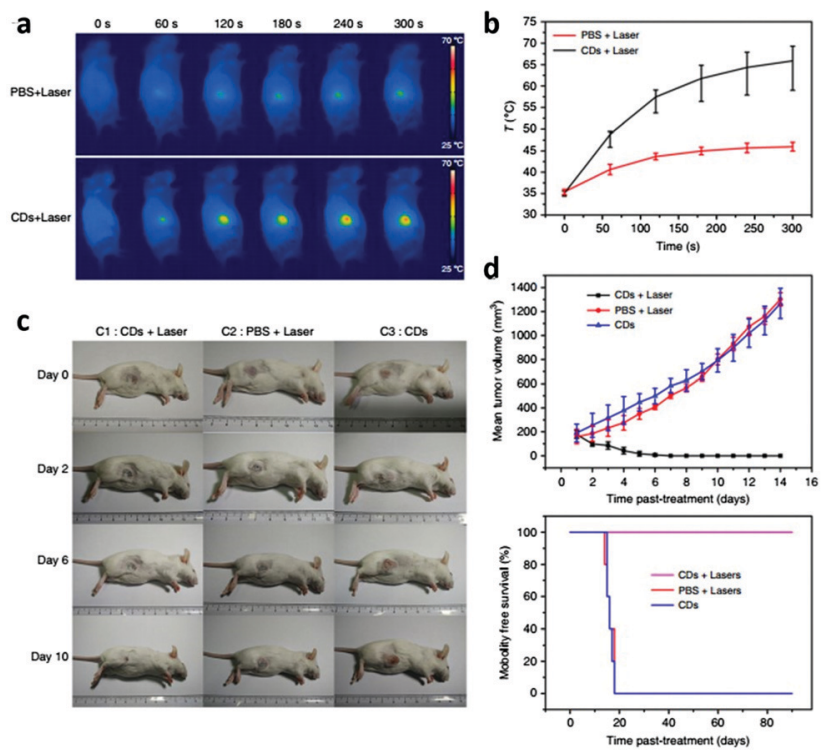

e
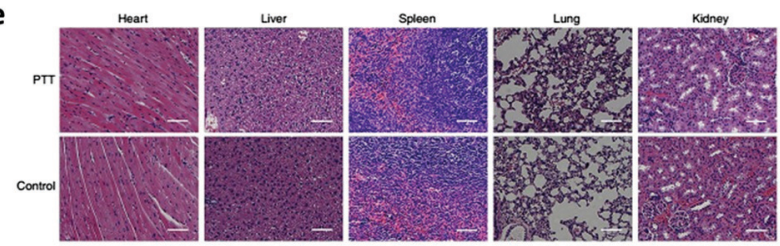

Fig. 11 Photothermal therapy via intravenous injection based on CDs. (a) IR thermal images of mice with intravenous CDs injected at $10,60,120$, 180,240 , and $300 \mathrm{~s}$ under irradiation at the tumour region with a $655 \mathrm{~nm}$ laser at $1 \mathrm{~W} \mathrm{~cm}^{-2}$. (b) Temperature at mouse tumour sites as a function of the irradiation duration. (c) Photographs that document H22 tumour development on several days in live mice under various treatment conditions. (d) Tumour growth curves of $\mathrm{H} 22$ tumours in mice and survival rates of the groups after therapy. (e) Hematoxylin and eosin (H\&E)-stained slices of heart, liver, spleen, lung, and kidney tissues of mice after PTT and control treatments. Scale bar: $50 \mu \mathrm{m}$. Reprinted with permission from ref. 134. Copyright 2018 Springer Nature Publishing AG.

CDs under irradiation is becoming a major concern in cancer therapy, which provides a unique opportunity to use CDs as PDT agents by enhancing their ability to kill tumour cells. For the first time, CDs were found to generate ROS under irradiation with blue light in vitro for application in PDT in 2011. ${ }^{137}$ However, the blue-emission CDs could hardly be used in clinical application due to their shallow tissue penetration. Accordingly, red-emission CDs were then introduced due to the non-invasive nature, minimum autofluorescence background of bio-samples and deep tissue penetration. ${ }^{139}$ Highly waterdispersible CDs (emission peak at $680 \mathrm{~nm}$ ) were prepared using a hydrothermal method with polythiophene derivatives (PT2) as the carbon source. ${ }^{57}$ Through in vitro and in vivo studies, it was demonstrated that the CDs could be used as PDT agents with good biocompatibility and excellent ROS generation capability via a multistate sensitization process. It was first demonstrated that the CDs with a high ROS generating efficiency acted as a PDT agent for cancer treatment in vivo. Subsequently, other CDs with red emission were developed (emission peak at $640 \mathrm{~nm}$ ) using polythiophene phenylpropionic acid as a precursor. ${ }^{140}$ 


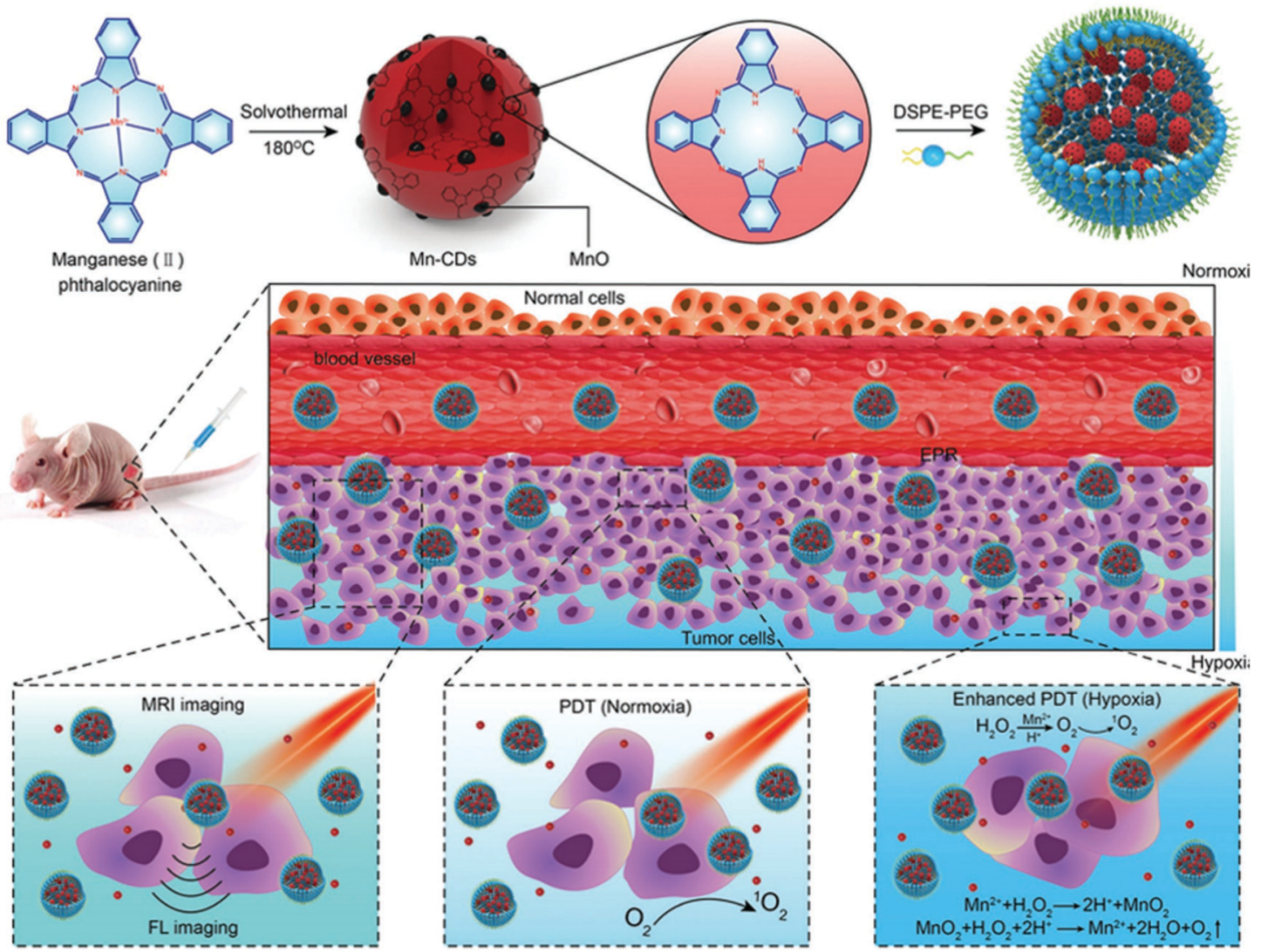

Fig. 12 Schematic illustration of the $\mathrm{Mn}-\mathrm{CD}$ assembly as an acidic $\mathrm{H}_{2} \mathrm{O}_{2}$-driven oxygenerator to enhance the anticancer efficiency of PDT in a solid tumour. Reprinted with permission from ref. 143. Copyright 2018 John Wiley and Sons.

More importantly, a high photothermal conversion efficiency of $38.5 \%$ under NIR light irradiation was also realized, which significantly broadened the applications of CDs in photothermalsynergistic therapy. Due to the oxygen dependence of PDT, hypoxia resulting from the rapid consumption of oxygen in the PDT process would reduce the therapeutic effect. ${ }^{141}$ Because the oxygen supply is reduced in the tumour microenvironment, hypoxia is commonly found in most solid tumours. Therefore, the inadequate oxygen supply in tumours prevents PDT from achieving its full therapeutic potential. ${ }^{142}$ In order to overcome these difficulties resulting from the hypoxia in the PDT process, magnetofluorescent Mn-CDs were prepared by using manganese(II) phthalocyanine as a precursor. ${ }^{143}$ Significantly, the Mn-CDs can not only effectively produce ROS but highly catalyze the generation of oxygen as well (Fig. 12). Thanks to the catalysis of Mn-CDs, the tumour hypoxia was improved and enhanced PDT was then achieved. This work considerably broadened the scope of CDs in the biomedical field and provided a versatile strategy for PDT.

Further significant therapeutic potential of CDs is their ability to serve as carriers of chemotherapeutic drugs to improve the delivery efficiency or offer benefits in the therapeutic effect. ${ }^{144}$ For instance, GQD-based drug delivery highlighted that attaching the tumour-targeting module biotin (vitamin $\mathrm{K}$ or vitamin B7) on the edge of GQDs specifically recognized the receptors overexpressed on cancer cells and led to the increased internalization of GQDs. This study explored a new biocompatible and cell-traceable drug delivery system, which was able to release DOX to cancer cells in a selective manner and minimize the anticancer drug systemic toxicity and undesirable side effects. Based on arginine-glycine-aspartic acid-modified GQDs loaded with DOX, a biocompatible and multifunctional drug delivery system for the targeted treatment of prostate cancer was developed. ${ }^{145}$ Surface modification of the GQD-based drug delivery system with RGD facilitated the internalization of GQDs and consequentially enhanced the availability and effect of the carried DOX. ${ }^{106}$

Tumour gene therapy describes the technique of delivering genetic materials to tumour cells in order to treat cancers. Similar to the requirements for drug delivery systems, effective carriers in gene therapy are capable of bypassing biological barriers to ensure delivery of the genetic materials into cells. ${ }^{146}$ While viral vectors are effective in gene delivery due to their natural ability to invade and deliver their genetic material, the barrier of immunogenicity induced by viral vectors has kept them far from safe for clinical use. ${ }^{147}$ Due to the traits of being an effective gene carrier, CDs have attracted great attention as non-viral vectors in gene therapy. A study in 2017 showed that CDs could be well applied in gene delivery. ${ }^{148}$ Non-toxic GQDs with two green and red emission colors were synthesized by Hummers' method and the GQDs could be conjugated with the MPG-2H1 chimeric peptide and plasmid DNA (pDNA) by noncovalent interactions. The GQDs could allow efficient tracking 
and enhanced internalization of the plasmid harboring the firefly luciferase gene into HEK 293T cells and the results of confocal microscopy demonstrated that their construct can be considered as a nontoxic carrier with dual functions of gene delivery and nuclear targeting. This study suggests that CDs are a promising transfection vector that could lead to more in vitro and in vivo applications of CD-based gene therapy. Up to now, some CD-based non-viral vectors for delivery of genetic material have been investigated in in vivo and in vitro experiments. Based on their interesting properties, CDs have great potential as genetic material carriers in clinical studies.

\section{Conclusions and perspectives}

In this review, we summarize the recent research progress of CDs on the synthesis and optical properties with a critical survey which addressed in detail their advanced applications in biomedicine. The intriguing merits of CDs are highlighted in their applications for bioimaging including of stem cells and tumour cells, TP fluorescence imaging, red or NIR emission for in vivo imaging, biosensing, cancer therapy including photodynamic therapy, photothermal therapy and chemotherapy. There is no doubt that the development of CDs for biomedical applications has seen great progress within a short time. However, future research still faces challenges in terms of fundamental understanding and practical applications as will be stated below.

For bioimaging, due to their minimal photodamage, low interference from autofluorescence with biological tissues, minimum tissue absorption, and deep tissue penetration, NIR-II fluorescence properties of CDs (1000-1700 nm) are highly desired. Up to now, a number of studies have acquired efficient NIR-I emission CDs. In this regard, more in-depth research should be carried out to address this issue, which is expect to direct the rational design of CDs for bioimaging. In addition, radiotherapy has significantly increased patients' overall survival and quality of life in the current clinic. Radioactive labelling of CDs is one of the most meaningful tasks which should be further explored in in vivo imaging. Moreover, radioactive labelled CDs can help us systematically investigate the pharmacokinetics, biodistribution, and toxicology of this type of nanomaterials.

For cancer therapy, recent efforts have been primarily focused on engineering imaging or therapeutic agents through conjugation of ligands that recognize "receptor" molecules expressed on cancer cells or in the tumour microenvironment. First, receptor molecules that are exclusively expressed on the surface of cancer cells are quite rare, as most of them are also present in normal tissues. As a result, the accumulation of cargo agents in normal tissues cannot be avoided. Second, cancer represents a group of highly heterogeneous diseases. Cancers of different tissue origin or intra-tumour location often have distinct genotypes and phenotypes. Consequently, they may not be targeted using a single ligand. Third, targeted imaging and drug delivery to tumours in the brain is further complicated by the blood-brain barrier (BBB), which prevents the penetration of most agents into the brain. Although there have been tremendous improvements in the clinical management of other tumours, the prognosis for most brain tumours remains dismal. Conventional intravenous chemotherapies, including those delivered via liposomes, are ineffective due to the limited entry across the BBB. Engineering drug delivery to the brain has been mainly attempted through traditional ligand-mediated targeted delivery, which has had limited success. The current approach to imaging intracranial tumours, which depends on the amount of contrast agent that penetrates through the leaky BBB, has been proved to be inadequate to detect infiltrative tumour cells in the region with the intact or less disruptive BBB. The development of high specificity and efficiency CDs for imaging and treatment of brain tumours remains a major challenge.

Despite these challenges, it is optimistic that the boom in carbon dots will advance their applications in bioimaging, biosensing and biotherapy. Through combinations of experimental and theoretical studies, more efforts should be made on developing biocompatible CDs and exploring their clinical applications.

\section{Conflicts of interest}

There are no conflicts to declare.

\section{Acknowledgements}

This work is supported by NSFC of China (21573019, 21872010). We also acknowledge the support from Key Laboratory of Radiopharmaceuticals and Key Laboratory of Theoretical and Computational Photochemistry, Ministry of Education.

\section{Notes and references}

1 K. A. S. Fernando, S. Sahu, Y. Liu, W. K. Lewis, E. A. Guliants, A. Jafariyan, P. Wang, C. E. Bunker and Y. P. Sun, ACS Appl. Mater. Interfaces, 2015, 7, 8363-8376.

2 C. Q. Ding, A. W. Zhu and Y. Tian, Acc. Chem. Res., 2014, 47, 20-30.

3 H. J. Sun, L. Wu, W. L. Wei and X. G. Qu, Mater. Today, 2013, 16, 433-442.

4 H. T. Li, X. D. He, Z. H. Kang, H. Huang, Y. Liu, J. L. Liu, S. Y. Lian, C. H. A. Tsang, X. B. Yang and S. T. Lee, Angew. Chem., Int. Ed., 2010, 49, 4430-4434.

5 X. Xu, R. Ray, Y. L. Gu, H. J. Ploehn, L. Gearheart, K. Raker and W. A. Scrivens, J. Am. Chem. Soc., 2004, 126, 12736-12737.

6 Y. P. Sun, B. Zhou, Y. Lin, W. Wang, K. A. S. Fernando, P. Pathak, M. J. Meziani, B. A. Harruff, X. Wang, H. Wang, P. G. Luo, H. Yang, M. E. Kose, B. Chen, L. M. Veca and S. Y. Xie, J. Am. Chem. Soc., 2006, 128, 7756-7757.

7 R. Mohammadinejad, S. Karimi, S. Iravani and R. S. Varma, Green Chem., 2016, 18, 20-52.

8 M. Baldrighi, M. Trusel, R. Tonini and S. Giordani, Front. Neurosci., 2016, 10, 250. 
9 T. Meng, T. Yuan, X. H. Li, Y. C. Li, L. Z. Fan and S. Yang, Chem. Commun., 2019, 55, 6531-6534.

10 Q. Guo, F. L. Yuan, B. Zhang, S. J. Zhou, J. Zhang, Y. M. Bai, L. Z. Fan, T. Hayat, A. Alsaedi and Z. A. Tan, Nanoscale, 2019, 11, 115-124.

11 F. L. Yuan, Z. F. Xi, X. Y. Shi, Y. C. Li, X. H. Li, Z. N. Wang, L. Z. Fan and S. H. Yang, Adv. Opt. Mater., 2019, 7, 1801202.

12 Y. B. Yan, J. Gong, J. Chen, Z. P. Zeng, W. Huang, K. Y. Pu, J. Y. Liu and P. Chen, Adv. Mater., 2019, 31, 1808283.

13 H. Ding, S. B. Yu, J. S. Wei and H. M. Xiong, ACS Nano, 2016, 10, 484-491.

14 H. Ding, J. S. Wei, P. Zhang, Z. Y. Zhou, Q. Y. Gao and H. M. Xiong, Small, 2018, 14, 1800612.

15 F. L. Yuan, Y. C. Li, X. H. Li, J. Zhu, L. Z. Fan, S. X. Zhou, Y. R. Zhang and J. B. Zhou, ACS Appl. Bio. Mater., 2018, 1, 853-858.

16 S. Y. Lim, W. Shen and Z. Q. Gao, Chem. Soc. Rev., 2015, 44, 362-381.

17 A. L. Antaris, J. T. Robinson, O. K. Yaghi, G. Hong, S. Diao, R. Luong and H. Dai, ACS Nano, 2013, 7, 3644-3652.

18 S. J. Zhu, Q. N. Meng, L. Wang, J. H. Zhang, Y. B. Song, H. Jin, K. Zhang, H. C. Sun, H. Y. Wang and B. Yang, Angew. Chem., Int. Ed., 2013, 52, 3953-3957.

19 R. Wang, K. Q. Lu, Z. R. Tang and Y. J. Xu, J. Mater. Chem. A, 2017, 5, 3717-3734.

20 S. H. Li, S. X. Zhou, Y. C. Li, X. H. Li, J. Zhu, L. Z. Fan and S. H. Yang, ACS Appl. Mater. Interfaces, 2017, 9, 22332-22341.

21 H. T. Lu, W. J. Li, H. F. Dong and M. L. Wei, Small, 2019, 0, 1902136.

22 F. L. Yuan, S. H. Li, Z. T. Fan, X. Y. Meng, L. Z. Fan and S. H. Yang, Nano Today, 2016, 11, 565-586.

23 Y. Li, Y. Zhao, H. H. Cheng, Y. Hu, G. Q. Shi, L. M. Dai and L. T. Qu, J. Am. Chem. Soc., 2012, 134, 15-18.

24 L. Cao, X. Wang, M. J. Meziani, F. S. Lu, H. F. Wang, P. G. Luo, Y. Lin, B. A. Harruff, L. M. Veca, D. Murray, S. Y. Xie and Y. P. Sun, J. Am. Chem. Soc., 2007, 129, 11318-11319.

25 S. Pandit, P. Behera, J. Sahoo and M. De, ACS Appl. Bio. Mater., 2019, 2, 3393-3403.

26 T. Malina, K. Poláková, J. Skopalík, V. Milotová, K. Holá, M. Havrdová, K. B. Tománková, V. Čmiel, L. Šefc and R. Zbořil, Carbon, 2019, 152, 434-443.

27 S. Fasbender, L. Zimmermann, R. P. Cadeddu, M. Luysberg, B. Moll, C. Janiak, T. Heinzel and R. Haas, Sci. Rep., 2019, 9, 12028.

28 A. B. Ganganboina and R. A. Doong, Sci. Rep., 2019, 9, 7214.

29 D. Kim, J. M. Yoo, H. Hwang, J. Lee, S. H. Lee, S. P. Yun, M. J. Park, M. Lee, S. Choi, S. H. Kwon, S. Lee, S. H. Kwon, S. Kim, Y. J. Park, M. Kinoshita, Y.-H. Lee, S. Shin, S. R. Paik, S. J. Lee, S. Lee, B. H. Hong and H. S. Ko, Nat. Nanotechnol., 2018, 13, 812-818.

30 C. Wang, C. Y. Wu, X. J. Zhou, T. Han, X. Z. Xin, J. Y. Wu, J. Y. Zhang and S. W. Guo, Sci. Rep., 2013, 3, 2852.

31 K. P. Carter, A. M. Young and A. E. Palmer, Chem. Rev., 2014, 114, 4564-4601.

32 D. Jariwala, V. K. Sangwan, L. J. Lauhon, T. J. Marks and M. C. Hersam, Chem. Soc. Rev., 2013, 42, 2824-2860.
33 W. Wang, Y. C. Lu, H. Huang, A. J. Wang, J. R. Chen and J. J. Feng, Biosens. Bioelectron., 2015, 64, 517-522.

34 A. Razzazan, F. Atyabi, B. Kazemi and R. Dinarvand, Mater. Sci. Eng., C, 2016, 62, 614-625.

35 X. J. Gong, Q. Y. Zhang, Y. F. Gao, S. M. Shuang, M. M. F. Choi and C. Dong, ACS Appl. Mater. Interfaces, 2016, 8, 11288-11297.

36 X. Sui, C. Luo, C. Wang, F. W. Zhang, J. Y. Zhang and S. W. Guo, Nanomedicine, 2016, 12, 1997-2006.

37 T. Feng, X. Z. Ai, G. H. An, P. P. Yang and Y. L. Zhao, ACS Nano, 2016, 10, 4410-4420.

38 K. Yang, L. Z. Feng and Z. Liu, Adv. Drug Delivery Rev., 2016, 105, 228-241.

39 D. Q. Chen, C. A. Dougherty, K. Zhu and H. Hong, J. Controlled Release, 2015, 210, 230-245.

40 T. Yuan, T. Meng, P. He, Y. X. Shi, Y. C. Li, X. H. Li, L. Z. Fan and S. H. Yang, J. Mater. Chem. C, 2019, 7, 6820-6835.

41 J. J. Du, N. Xu, J. L. Fan, W. Sun and X. J. Peng, Small, 2019, 15, 1805087.

42 F. L. Yuan, Z. B. Wang, X. H. Li, Y. C. Li, Z. A. Tan, L. Z. Fan and S. H. Yang, Adv. Mater., 2017, 29, 1604436.

43 F. Yuan, P. He, Z. F. Xi, X. H. Li, Y. C. Li, H. Z. Zhong, L. Z. Fan and S. H. Yang, Nano Res., 2019, 12, 1669-1674.

44 Z. M. Luo, G. Q. Qi, K. Y. Chen, M. Zou, L. H. Yuwen, X. W. Zhang, W. Huang and L. H. Wang, Adv. Funct. Mater., 2016, 26, 2739-2744.

45 S. H. Jin, D. H. Kim, G. H. Jun, S. H. Hong and S. Jeon, ACS Nano, 2013, 7, 1239-1245.

46 H. Yoon, Y. H. Chang, S. H. Song, E. S. Lee, S. H. Jin, C. Park, J. Lee, B. H. Kim, H. J. Kang, Y. H. Kim and S. Jeon, Adv. Mater., 2016, 28, 5255-5261.

47 H. S. Han, J. S. Lee, J. H. Ryu, K. M. Kim, J. L. Jones, J. Lim, S. Guillemet-Fritsch, H. C. Lee and S. Mhin, J. Phys. Chem. C, 2016, 120, 13667-13674.

48 Y. Li, Y. Hu, Y. Zhao, G. Q. Shi, L. Deng, Y. B. Hou and L. Qu, Adv. Mater., 2011, 23, 776-780.

49 D. Y. Pan, J. C. Zhang, Z. Li and M. H. Wu, Adv. Mater., 2010, 22, 734-738.

50 J. Joseph and A. A. Anappara, ChemPhysChem, 2017, 18, 292-298.

51 S. J. Zhuo, M. W. Shao and S. T. Lee, ACS Nano, 2012, 6, 1059-1064.

52 D. B. Shinde and V. K. Pillai, Chem. - Eur. J., 2012, 18, 12522-12528.

53 M. Zhang, L. L. Bai, W. H. Shang, W. J. Xie, H. Ma, Y. Y. Fu, D. C. Fang, H. Sun, L. Z. Fan, M. Han, C. M. Liu and S. H. Yang, J. Mater. Chem., 2012, 22, 7461-7467.

54 Z. T. Fan, S. X. Zhou, C. Garcia, L. Z. Fan and J. B. Zhou, Nanoscale, 2017, 9, 4928-4933.

55 L. L. Li, G. H. Wu, G. H. Yang, J. Peng, J. W. Zhao and J. J. Zhu, Nanoscale, 2013, 5, 4015-4039.

56 J. Lu, P. S. E. Yeo, C. K. Gan, P. Wu and K. P. Loh, Nat. Nanotechnol., 2011, 6, 247.

57 J. C. Ge, M. H. Lan, B. J. Zhou, W. M. Liu, L. Guo, H. Wang, Q. Y. Jia, G. L. Niu, X. Huang, H. Y. Zhou, X. M. Meng, P. F. Wang, C. S. Lee, W. J. Zhang and X. D. Han, Nat. Commun., 2014, 5, 4596. 
58 R. L. Liu, D. Q. Wu, X. L. Feng and K. Müllen, J. Am. Chem. Soc., 2011, 133, 15221-15223.

59 W. X. Meng, X. Bai, B. Y. Wang, Z. Y. Liu, S. Y. Lu and B. Yang, Energy Environ. Mater., 2019, 1-21.

60 V. Sharma, P. Tiwari and S. M. Mobin, J. Mater. Chem. B, 2017, 5, 8904-8924.

61 E. L. Bentzen, I. D. Tomlinson, J. Mason, P. Gresch, M. R. Warnement, D. Wright, E. Sanders-Bush, R. Blakely and S. J. Rosenthal, Bioconjugate Chem., 2005, 16, 1488-1494.

62 J. H. Shen, Y. H. Zhu, X. L. Yang, J. Zong, J. M. Zhang and C. Z. Li, New J. Chem., 2012, 36, 97-101.

63 L. Wang, W. Li, B. Wu, Z. Li, S. L. Wang, Y. Liu, D. Y. Pan and M. H. Wu, Chem. Eng. J., 2016, 300, 75-82.

64 C. H. Lee, R. Rajendran, M.-S. Jeong, H. Y. Ko, J. Y. Joo, S. Cho, Y. W. Chang and S. Kim, Chem. Commun., 2013, 49, 6543-6545.

65 X. W. Zhao, J. L. Zhang, L. H. Shi, M. Xian, C. Dong and S. M. Shuang, RSC Adv., 2017, 7, 42159-42167.

66 Z. Wang, F. Yuan, X. Li, Y. Li, H. Zhong, L. Fan and S. Yang, Adv. Mater., 2017, 29, 1702910.

67 J. C. Ge, M. H. Lan, B. J. Zhou, W. M. Liu, L. Guo, H. Wang, Q. Y. Jia, G. L. Niu, X. Huang, H. Y. Zhou, X. M. Meng, P. F. Wang, C. S. Lee, W. J. Zhang and X. D. Han, Nat. Commun., 2014, 5, 4596.

68 L. Tang, R. B. Ji, X. M. Li, G. X. Bai, C. P. Liu, J. H. Hao, J. Y. Lin, H. X. Jiang, K. S. Teng, Z. B. Yang and S. P. Lau, ACS Nano, 2014, 8, 6312-6320.

69 F. L. Yuan, T. Yuan, L. Z. Sui, Z. B. Wang, Z. F. Xi, Y. C. Li, X. H. Li, L. Z. Fan, Z. A. Tan, A. Chen, M. X. Jin and S. H. Yang, Nat. Commun., 2018, 9, 2249.

70 D. Li, P. T. Jing, L. H. Sun, Y. An, X. Y. Shan, X. H. Lu, D. Zhou, D. Han, D. Z. Shen, Y. C. Zhai, S. N. Qu, R. Zbořil and A. L. Rogach, Adv. Mater., 2018, 30, 1705913.

71 H. R. Jia, Z. B. Wang, T. Yuan, F. L. Yuan, X. H. Li, Y. C. Li, Z. A. Tan, L. Z. Fan and S. H. Yang, Adv. Sci., 2019, 6, 1900397.

72 X. X. Shi, H. M. Meng, Y. Q. Sun, L. B. Qu, Y. H. Lin, Z. H. Li and D. Du, Small, 2019, 0, 1901507.

73 H. M. Kim and B. R. Cho, Chem. Rev., 2015, 115, 5014-5055.

74 H. Q. Tao, K. Yang, Z. Ma, J. M. Wan, Y. J. Zhang, Z. H. Kang and Z. Liu, Small, 2012, 8, 281-290.

75 L. P. Li, R. P. Zhang, C. X. Lu, J. H. Sun, L. J. Wang, B. T. Qu, T. T. Li, Y. D. Liu and S. J. Li, J. Mater. Chem. B, 2017, 5, 7328-7334.

76 Q. Y. Jia, X. L. Zheng, J. C. Ge, W. M. Liu, H. H. Ren, S. Q. Chen, Y. M. Wen, H. Y. Zhang, J. S. Wu and P. F. Wang, J. Colloid Interface Sci., 2018, 526, 302-311.

77 V. Singh, S. Kashyap, U. Yadav, A. Srivastava, A. V. Singh, R. K. Singh, S. K. Singh and P. S. Saxena, Toxicol. Res., 2019, 8, 395-406.

78 N. Abdullah, Al, J. E. Lee, I. In, H. Lee, K. D. Lee, J. H. Jeong and S. Y. Park, Mol. Pharmaceutics, 2013, 10, 3736-3744.

79 M. Nurunnabi, Z. Khatun, K. M. Huh, S. Y. Park, D. Y. Lee, K. J. Cho and Y. K. Lee, ACS Nano, 2013, 7, 6858-6867.

80 S. Fasbender, S. Allani, C. Wimmenauer, R. P. Cadeddu, K. Raba, J. C. Fischer, B. Bulat, M. Luysberg, C. A. M. Seidel, T. Heinzel and R. Haas, RSC Adv., 2017, 7, 12208-12216.
81 X. T. Zheng, A. Ananthanarayanan, K. Q. Luo and P. Chen, Small, 2015, 11, 1620-1636.

82 Y. T. Liu, S. X. Zhou, L. Z. Fan and H. Fan, Microchim. Acta, 2016, 183, 2605-2613.

83 Z. T. Fan, S. H. Li, F. L. Yuan and L. Z. Fan, RSC Adv., 2015, 5, 19773-19789.

84 Y. B. Song, S. J. Zhu and B. Yang, RSC Adv., 2014, 4, 27184-27200.

85 S. J. Zhu, J. H. Zhang, C. Y. Qiao, S. J. Tang, Y. F. Li, W. J. Yuan, B. Li, L. Tian, F. Liu, R. Hu, H. N. Gao, H. T. Wei, H. Zhang, H. C. Sun and B. Yang, Chem. Commun., 2011, 47, 6858-6860.

86 S. J. Zhu, J. H. Zhang, X. Liu, B. Li, X. F. Wang, S. J. Tang, Q. N. Meng, Y. F. Li, C. Shi, R. Hu and B. Yang, RSC Adv., 2012, 2, 2717-2720.

87 R. V. Nair, R. T. Thomas, V. Sankar, H. Muhammad, M. Dong and S. Pillai, ACS Omega, 2017, 2, 8051-8061.

88 K. X. Jin, H. Gao, L. H. Lai, Y. Q. Pang, S. Y. Zheng, Y. N. Niu and X. L. Li, J. Lumin., 2018, 197, 147-152.

89 Y. Fu, G. Y. Gao and J. F. Zhi, J. Mater. Chem. B, 2019, 7, 1494-1502.

90 R. S. Li, B. F. Yuan, J. H. Liu, M. L. Liu, P. F. Gao, Y. F. Li, M. Li and C. Z. Huang, J. Mater. Chem. B, 2017, 5, 8719-8724.

91 Y. Chong, Y. F. Ma, H. Shen, X. L. Tu, X. Zhou, J. Y. Xu, J. W. Dai, S. J. Fan and Z. J. Zhang, Biomaterials, 2014, 35, 5041-5048.

92 J. Dong, Y. L. Zhao, K. Q. Wang, H. Y. Chen, L. Liu, B. L. Sun, M. F. Yang, L. P. Sun, Y. Wang, X. G. Yu and L. F. Dong, ChemistrySelect, 2018, 3, 12696-12703.

93 X. Y. Tan, Y. C. Li, X. H. Li, S. X. Zhou, L. Z. Fan and S. H. Yang, Chem. Commun., 2015, 51, 2544-2546.

94 M. Zheng, S. B. Ruan, S. Liu, T. T. Sun, D. Qu, H. F. Zhao, Z. G. Xie, H. L. Gao, X. B. Jing and Z. C. Sun, ACS Nano, 2015, 9, 11455-11461.

95 Y. P. Zhang, J. M. Ma, Y. S. Yang, J. X. Ru, X. Y. Liu, Y. Ma and H. C. Guo, Spectrochim. Acta, Part A, 2019, 217, 60-67.

96 C. F. Hu, Y. L. Liu, Y. H. Yang, J. H. Cui, Z. R. Huang, Y. L. Wang, L. F. Yang, H. B. Wang, Y. Xiao and J. H. Rong, J. Mater. Chem. B, 2013, 1, 39-42.

97 M. Zhang, W. T. Wang, Y. J. Cui, N. L. Zhou and J. Shen, ACS Biomater. Sci. Eng., 2018, 4, 151-162.

98 H. C. Yao, W. W. Zhao, S. G. Zhang, X. F. Guo, Y. Li and B. Du, J. Mater. Chem. B, 2018, 6, 3107-3115.

99 Y. Song, X. Yan, Z. H. Li, L. B. Qu, C. Z. Zhu, R. F. Ye, S. Q. Li, D. Du and Y. H. Lin, J. Mater. Chem. B, 2018, 6, 3181-3187.

100 Y. Q. Dong, C. Q. Chen, X. T. Zheng, L. L. Gao, Z. M. Cui, H. B. Yang, C. X. Guo, Y. W. Chi and C. M. Li, J. Mater. Chem., 2012, 22, 8764-8766.

101 J. Peng, W. Gao, B. K. Gupta, Z. Liu, R. Romero-Aburto, L. H. Ge, L. Song, L. B. Alemany, X. B. Zhan, G. H. Gao, S. A. Vithayathil, B. A. Kaipparettu, A. A. Marti, T. Hayashi, J. J. Zhu and P. M. Ajayan, Nano Lett., 2012, 12, 844-849.

102 Z. T. Fan, Y. C. Li, X. H. Li, L. Z. Fan, S. X. Zhou, D. C. Fang and S. H. Yang, Carbon, 2014, 70, 149-156.

103 S. Sun, L. Zhang, K. Jiang, A. G. Wu and H. W. Lin, Chem. Mater., 2016, 28, 8659-8668. 
104 Q. Liu, B. D. Guo, Z. Y. Rao, B. H. Zhang and J. R. Gong, Nano Lett., 2013, 13, 2436-2441.

105 P. J. Fairchild, K. F. Nolan, S. Cartland and H. Waldmann, Int. Immunopharmacol., 2005, 5, 13-21.

106 G. C. Parker, M. Anastassova-Kristeva, H. E. Broxmeyer, W. H. Dodge, L. M. Eisenberg, U. M. Gehling, L. M. Guenin, R. Huss, N. I. Moldovan, M. Rao, E. F. Srour and M. C. Yoder, Stem Cells Dev., 2004, 13, 579-584.

107 W. H. Shang, X. Y. Zhang, M. Zhang, Z. T. Fan, Y. Sun, M. Han and L. Z. Fan, Nanoscale, 2014, 6, 5799-5806.

108 F. L. Yuan, L. Ding, Y. C. Li, X. H. Li, L. Z. Fan, S. X. Zhou, D. C. Fang and S. H. Yang, Nanoscale, 2015, 7, 11727-11733.

109 K. Jiang, S. Sun, L. Zhang, Y. Lu, A. Wu, C. Z. Cai and H. W. Lin, Angew. Chem., Int. Ed., 2015, 54, 5360-5363.

110 M. Havrdova, K. Hola, J. Skopalik, K. Tomankova, M. Petr, K. Cepe, K. Polakova, J. Tucek, A. B. Bourlinos and R. Zboril, Carbon, 2016, 99, 238-248.

111 K. Jiang, S. Sun, L. Zhang, Y. H. Wang, C. Z. Cai and H. W. Lin, ACS Appl. Mater. Interfaces, 2015, 7, 23231-23238.

112 L. H. Shi, Y. Y. Li, X. F. Li, X. P. Wen, G. M. Zhang, J. Yang, C. Dong and S. M. Shuang, Nanoscale, 2015, 7, 7394-7401.

113 Y. E, L. Bai, L. Fan, M. Han, X. Zhang and S. Yang, J. Mater. Chem., 2011, 21, 819-823.

114 B. Bao, A. Ahmad, A. S. Azmi, S. Ali and F. H. Sarkar, Curr. Protoc. Pharmacol., 2013, 61, 14.25.11-14.25.14.

115 T. Reya, S. J. Morrison, M. F. Clarke and I. L. Weissman, Nature, 2001, 414, 105-111.

116 E. M. De Francesco, F. Sotgia and M. P. Lisanti, Biochem. J., 2018, 475, 1611-1634.

117 R. H. Guo, S. X. Zhou, Y. C. Li, X. H. Li, L. Z. Fan and N. H. Voelcker, ACS Appl. Mater. Interfaces, 2015, 7, 23958-23966.

118 S. T. Yang, L. Cao, P. G. Luo, F. S. Lu, X. Wang, H. F. Wang, M. J. Meziani, Y. F. Liu, G. Qi and Y. P. Sun, J. Am. Chem. Soc., 2009, 131, 11308-11309.

119 P. G. Luo, S. Sahu, S. T. Yang, S. K. Sonkar, J. P. Wang, H. F. Wang, G. E. LeCroy, L. Cao and Y. P. Sun, J. Mater. Chem. B, 2013, 1, 2116-2127.

120 L. Cao, S. T. Yang, X. Wang, P. G. Luo, J. H. Liu, S. Sahu, Y. M. Liu and Y. P. Sun, Theranostics, 2012, 2, 295-301.

121 Y. P. Li, T. Y. Lin, Y. Luo, Q. Q. Liu, W. W. Xiao, W. C. Guo, D. Lac, H. Y. Zhang, C. H. Feng, S. Wachsmann-Hogiu, J. H. Walton, S. R. Cherry, D. J. Rowland, D. Kukis, C. Pan and K. S. Lam, Nat. Commun., 2014, 5, 4712.

122 L. V. Wang and S. Hu, Science, 2012, 335, 1458-1462.

123 F. Liu, T. L. Liu, X. X. Xu, X. Y. Guo, N. Li, C. Y. Xiong, C. Li, H. Zhu and Z. Yang, Mol. Pharmaceutics, 2018, 15, 619-628.

124 H. Zhu, C. K. Zhao, F. Liu, L. X. Wang, J. N. Feng, C. C. Shou and Z. Yang, ACS Med. Chem. Lett., 2017, 8, 266-269.

125 Y. Wang, H. Song, G. Wang, X. Yang, J. Wang and H. Wei, J. Radioanal. Nucl. Chem., 2019, 319, 1119-1125.

126 S. P. Song, Y. Qin, Y. He, Q. Huang, C. H. Fan and H. Y. Chen, Chem. Soc. Rev., 2010, 39, 4234-4243.

127 U. Resch-Genger, M. Grabolle, S. Cavaliere-Jaricot, R. Nitschke and T. Nann, Nat. Methods, 2008, 5, 763.
128 S. A. Gomes, C. S. Vieira, D. B. Almeida, J. R. SantosMallet, R. F. Menna-Barreto, C. L. Cesar and D. Feder, Sensors, 2011, 11, 11664-11678.

129 C. E. Bradburne, J. B. Delehanty, K. Boeneman Gemmill, B. C. Mei, H. Mattoussi, K. Susumu, J. B. Blanco-Canosa, P. E. Dawson and I. L. Medintz, Bioconjugate Chem., 2013, 24, 1570-1583.

130 X. X. Wu, S. S. Sun, Y. H. Wang, J. L. Zhu, K. Jiang, Y. M. Leng, Q. H. Shu and H. W. Lin, Biosens. Bioelectron., 2017, 90, 501-507.

131 C. X. Wang, K. L. Jiang, Q. Wu, J. P. Wu and C. Zhang, Chem. - Eur. J., 2016, 22, 14475-14479.

132 W. L. Gao, Y. M. Zhou, C. G. Xu, M. X. Guo, Z. C. Qi, X. J. Peng and B. Gao, Sens. Actuators, B, 2019, 281, 905-911.

133 W. L. Gao, H. H. Song, X. Wang, X. Q. Liu, X. B. Pang, Y. M. Zhou, B. Gao and X. J. Peng, ACS Appl. Mater. Interfaces, 2018, 10, 1147-1154.

134 X. Bao, Y. Yuan, J. Q. Chen, B. H. Zhang, D. Li, D. Zhou, P. T. Jing, G. Y. Xu, Y. L. Wang, K. Holá, D. Shen, C. F. Wu, L. Song, C. B. Liu, R. Zbořil and S. N. Qu, Light: Sci. Appl., 2018, 7, 91.

135 W. M. Girma, K. Dehvari, Y. C. Ling and J. Y. Chang, Mater. Sci. Eng., C, 2019, 101, 179-189.

136 X. N. Jing, Z. Zhi, L. M. Jin, F. Wang, Y. S. Wu, D. Q. Wang, K. Yan, Y. P. Shao and L. J. Meng, Nanoscale, 2019, 11, 9457-9467.

137 I. L. Christensen, Y. P. Sun and P. Juzenas, J. Biomed. Nanotechnol., 2011, 7, 667-676.

138 Z. M. Markovic, B. Z. Ristic, K. M. Arsikin, D. G. Klisic, L. M. Harhaji-Trajkovic, B. M. Todorovic-Markovic, D. P. Kepic, T. K. Kravic-Stevovic, S. P. Jovanovic, M. M. Milenkovic, D. D. Milivojevic, V. Z. Bumbasirevic, M. D. Dramicanin and V. S. Trajkovic, Biomaterials, 2012, 33, 7084-7092.

139 P. Agostinis, K. Berg, K. A. Cengel, T. H. Foster, A. W. Girotti, S. O. Gollnick, S. M. Hahn, M. R. Hamblin, A. Juzeniene, D. Kessel, M. Korbelik, J. Moan, P. Mroz, D. Nowis, J. Piette, B. C. Wilson and J. Golab, Ca-Cancer J. Clin., 2011, 61, 250-281.

140 J. C. Ge, Q. Y. Jia, W. M. Liu, L. Guo, Q. Y. Liu, M. H. Lan, H. Y. Zhang, X. M. Meng and P. F. Wang, Adv. Mater., 2015, 27, 4169-4177.

141 J. P. Celli, B. Q. Spring, I. Rizvi, C. L. Evans, K. S. Samkoe, S. Verma, B. W. Pogue and T. Hasan, Chem. Rev., 2010, 110, 2795-2838.

142 M. Höckel and P. Vaupel, J. Natl. Cancer I., 2001, 93, 266-276. 143 Q. Y. Jia, J. C. Ge, W. M. Liu, X. L. Zheng, S. Q. Chen, Y. M. Wen, H. Y. Zhang and P. F. Wang, Adv. Mater., 2018, 30, 1706090.

144 K. Hola, Y. Zhang, Y. Wang, E. P. Giannelis, R. Zboril and A. L. Rogach, Nano Today, 2014, 9, 590-603.

145 J. C. Qiu, R. B. Zhang, J. H. Li, Y. H. Sang, W. Tang, P. Rivera Gil and H. Liu, Int. J. Nanomed., 2015, 10, 6709-6724.

146 C. E. Dunbar, K. A. High, J. K. Joung, D. B. Kohn, K. Ozawa and M. Sadelain, Science, 2018, 359, eaan4672.

147 C. L. Hardee, L. M. Arevalo-Soliz, B. D. Hornstein and L. Zechiedrich, Genes, 2017, 8, 65.

148 S. M. Ghafary, M. Nikkhah, S. Hatamie and S. Hosseinkhani, Sci. Rep., 2017, 7, 9552. 